[r^v] أ. م. مرسي مشري

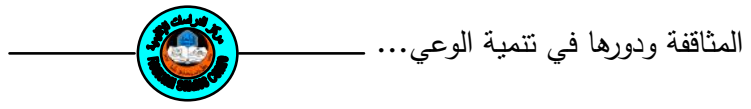

المثاقفة ودورها في تنمية الوعي السياسي لاى الشباب العربي

\author{
مرسي مشري \\ أستاذ مساعد/ قسم العلوم السياسية/ جامعة الثلف- الجزائر
}

مستخلص البحث

يعد مفهوم التثاقف (التكيف الثقافي) مسن بين المفاهيم السوسيوثقافية الحديثة

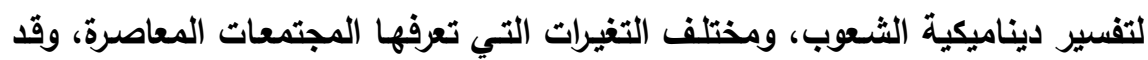

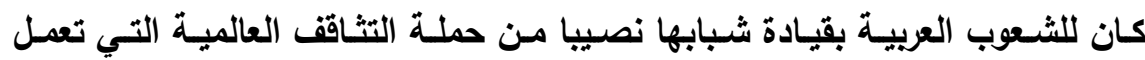

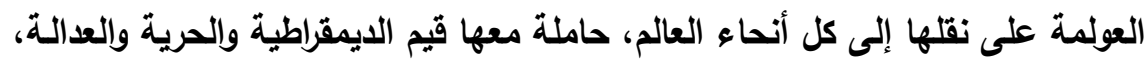

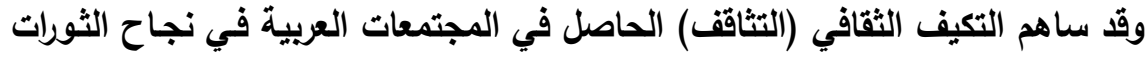

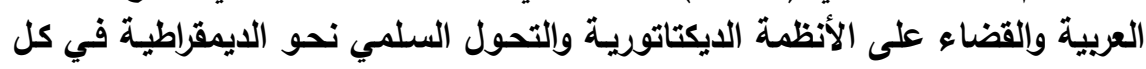

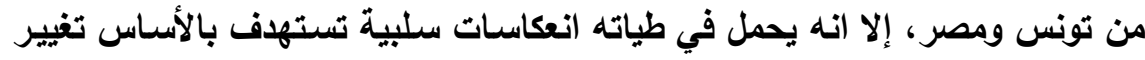

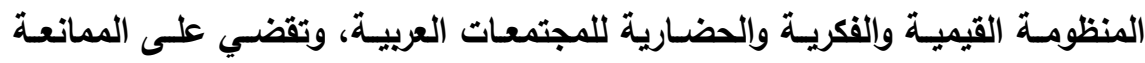

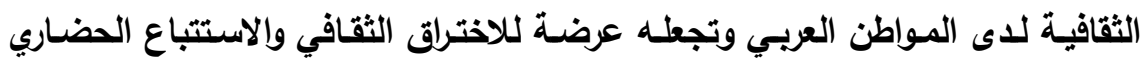
للحضارة الغربية وفقاً لما تهاف لإليه العربه وتجوله

مقدمة

يعد مفهوم التثاقف (التكيف التقافي) مـن بين المفـاهيم السوسـيوثقافية الحديثة لتفسير حركيـة الثـعوب الثـعوب، ومختلف التخيرات التي تعرفها

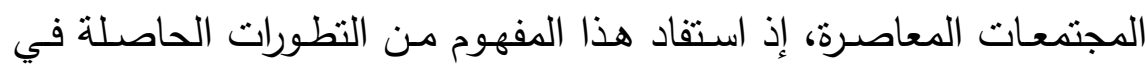

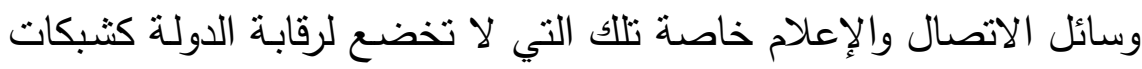

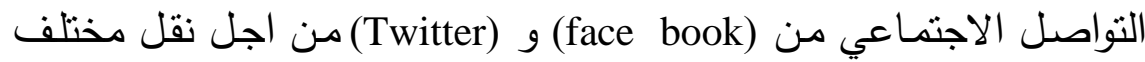

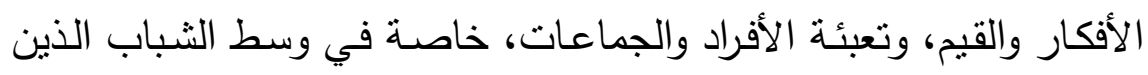
يتوقون إلى التعرف على مختلف الثقافات والحضارات. 
وقد كان للشعوب العربية بقيادة شبابها نصيبا من حملة التثاقف العالمية

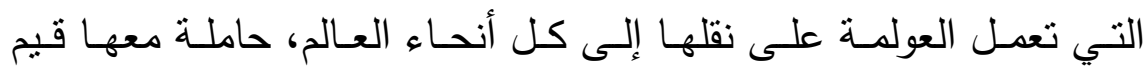
الديمقراطية والحريـة والعدالة، إذ استغلت حاجتين لدى الثباب العربي كان دائما يسعى لإشباعهما وهما: حاجة العيش على الطريقة الغربية من خلال إلى

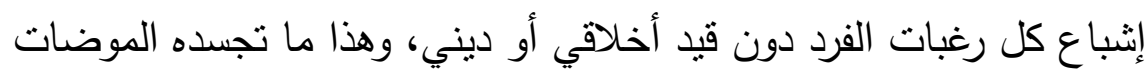

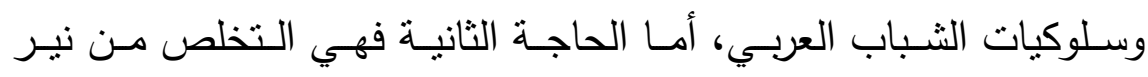
العبودية والاضطهاد الذي مارسته عليه الأنظمة العربية المستبدة لمدد زمنية

طويلة.

لقد أسـهم التكيف الثقافي الحاصـل في المجتمعـات العربيـة في نجـاح الثورات العربيـة والقضـاء على الأنظمـة الديكتاتوريـة والتحول السـلمي نحو فئه الديمقراطية في كل من تونس ومصر ، إلا انه يحمل في طياته انعكاسات

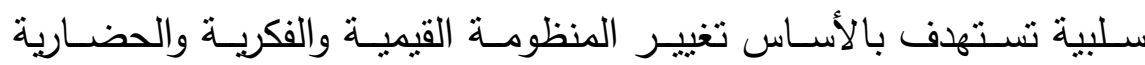

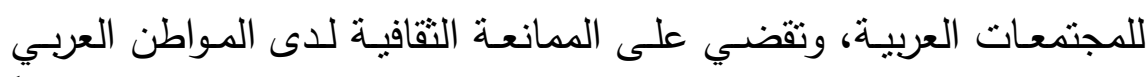
وتجعله عرضة للاختراق الثقافي والاستتباع الحضاري للحضـارة الغربية وفقاً لما تهدف إليه العولمة. من هنا تتبع أهمية الموضوع وإثكاليته المتمحورة حول مكانة النثاقف ودوره في تتمية الوعي السياسـي لدى المواطن العربي، ومن ثم دفعسه إلى ولى

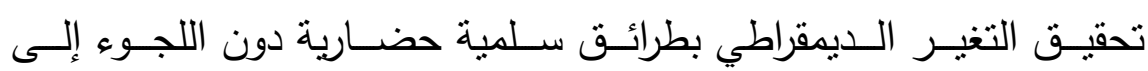

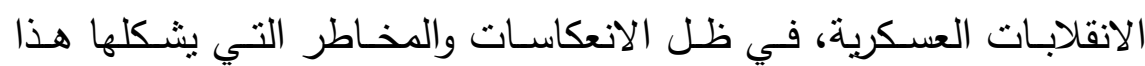
المفهوم على الهويـة العربية الإسـامية، أي: هل يمكن للتئناقف أن يكون

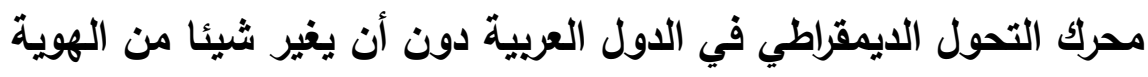

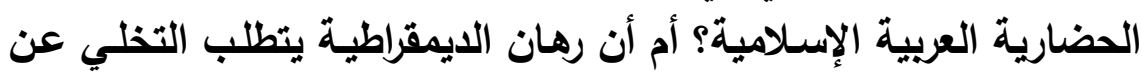

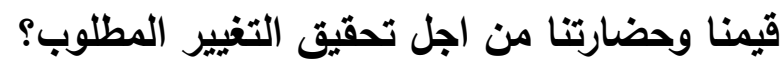


أولاً: الإطار المفاهيمي للتثاقف وعلاقته ببعض المفاهيم الأخرى

1- مفهوم التثاقف

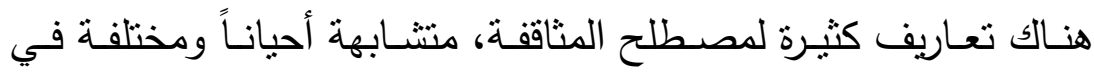
سياقات أخرى، إذ نميز اتجاهان في تعريف المصطلح:

\section{الاتجاه الأول}

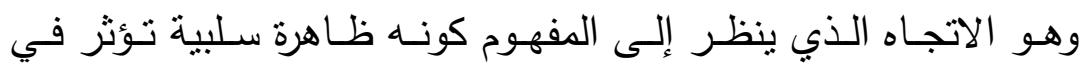

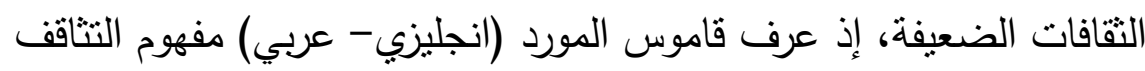
Acculturation

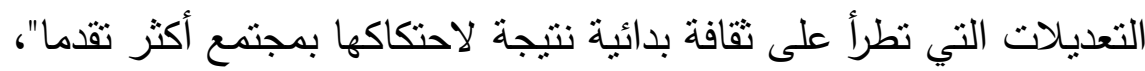

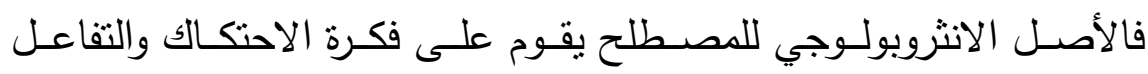

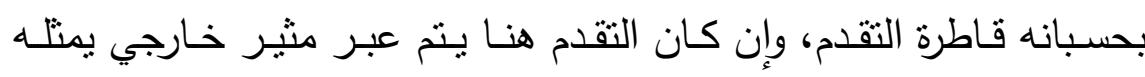
المجتمع "الأكثر تقدما". وفي تعريــ آخر فالمثاقفة تقيد تأثير نقافـة قويـة أو مستقوية وغازيـة وقاهرة على ثقافة ضعيفة أو مستضعفة ومغزوة ومقهورة، وهي حال الثقافة الغربية الاستعمارية في بلدان الثمال على التقافات القومية والوطنية المحلية

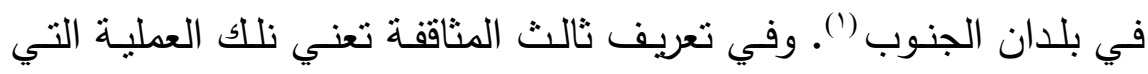

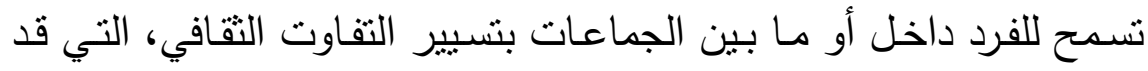

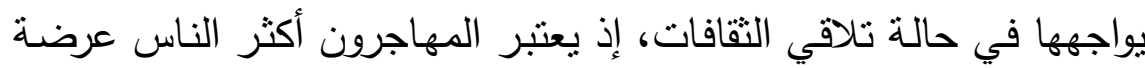

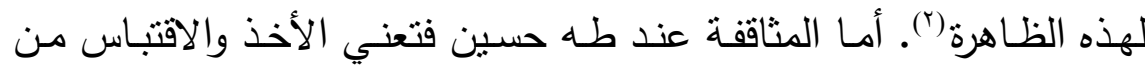

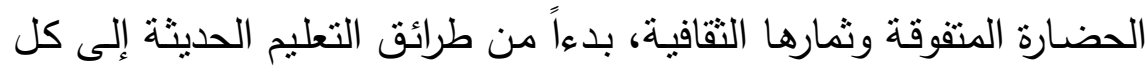
أشكال التعبير الأدبي الجديدة علينا كالرواية والمسرحية والمقالة، وأما وسيلة

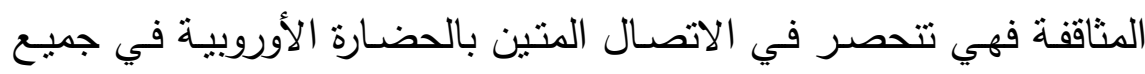

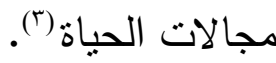


الاتجاه الثاني

نظر أنصاره إلى المصطلح نظرة ايجابية بحسبانه محركا لتقدم الحضارة

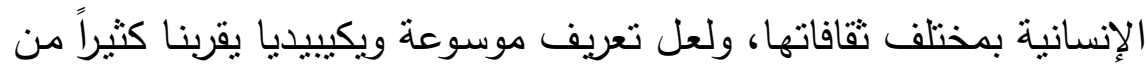

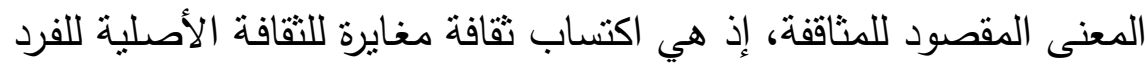

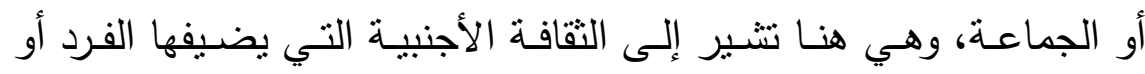

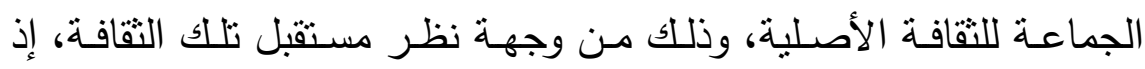
تضاف التقافة الجديدة إلى أو تختلط بثقافة الفرد أو الجماعة المكتسبة محليا

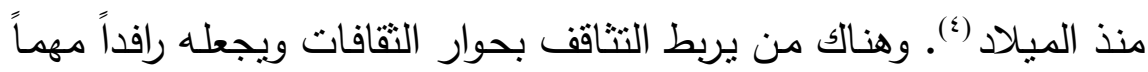

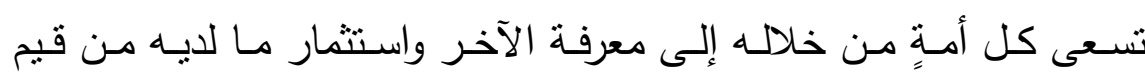

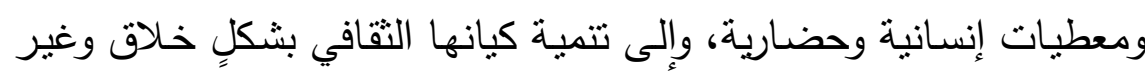

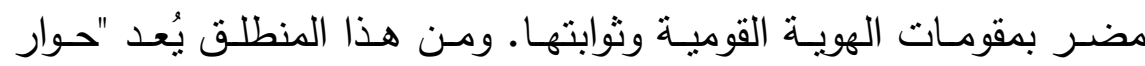

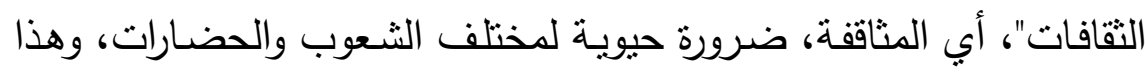

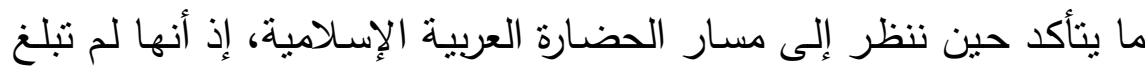

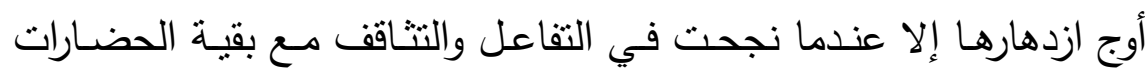

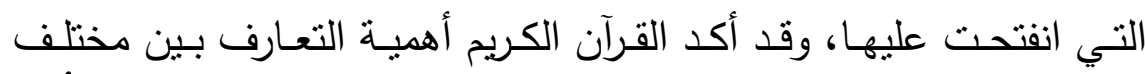

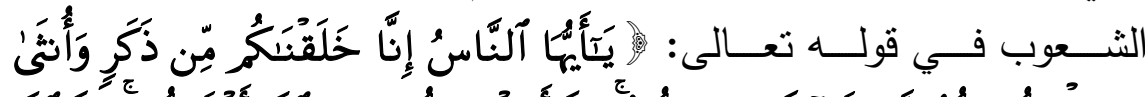

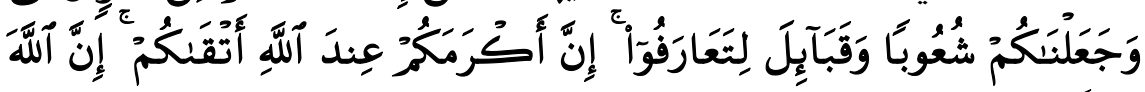

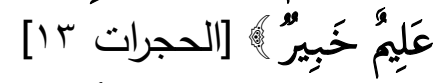

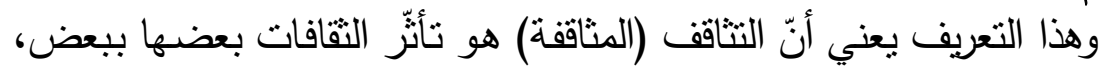

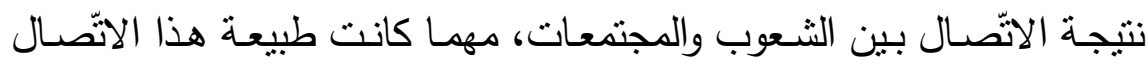

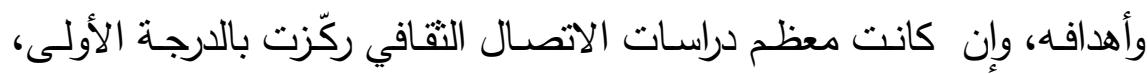

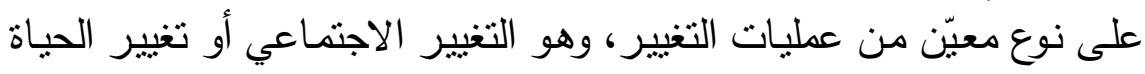
الاجتماعية، وانعكاس ذللك التغيير على التقافة (ْ). 
أمسا تعريف لجنـة مجلس البحث الاجتماعي فيرى أن: "التثاقف بثـمل

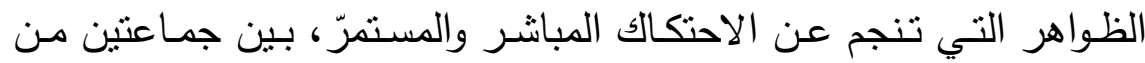

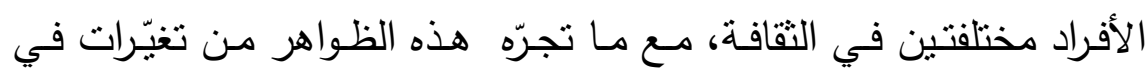

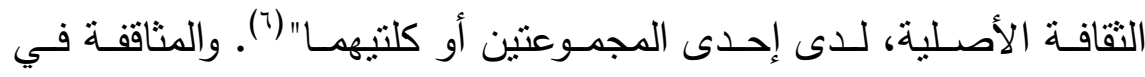

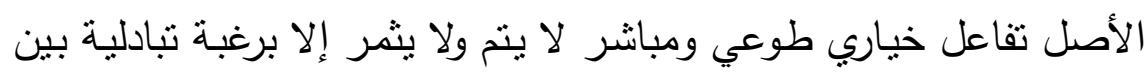

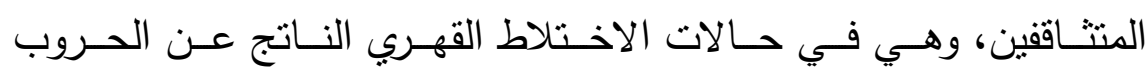
والاستعمار لا يمكن أن تتحقق، وتكون نتيجة الإختلاط الناجم عن ذلك التك

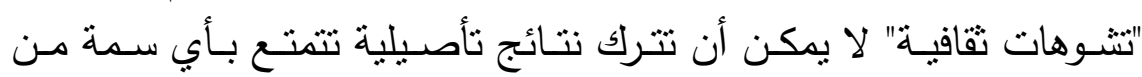

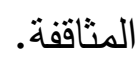
وعلى الرغم من أن المناقفة مصطلح حديث (لان، يوحي تركيبه اللغوي

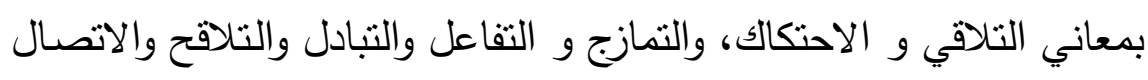

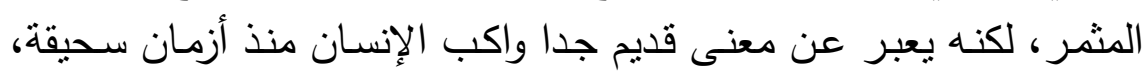

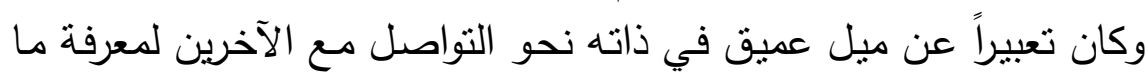

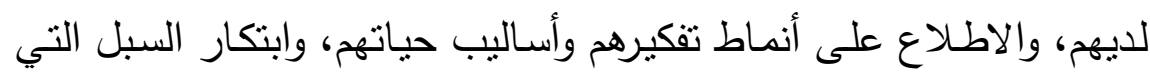

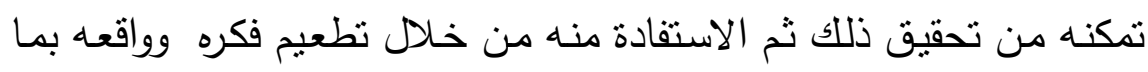

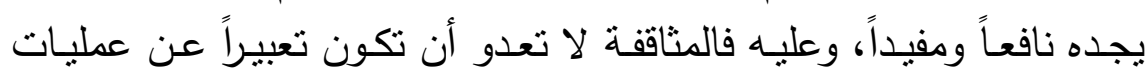

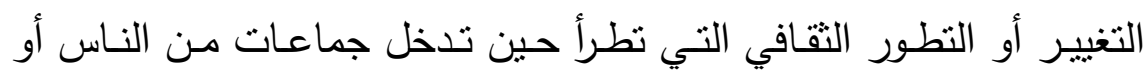

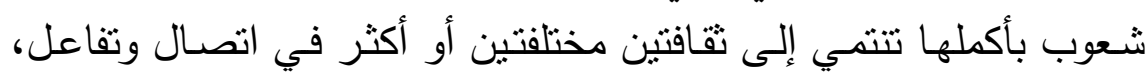

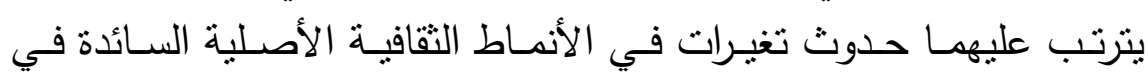

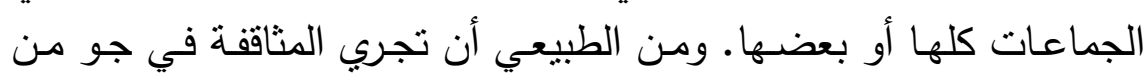

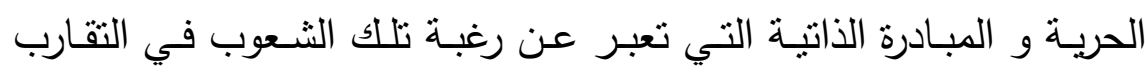

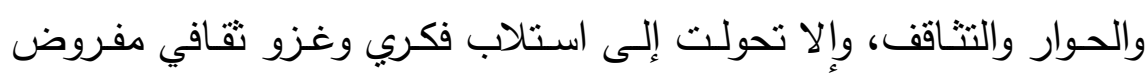

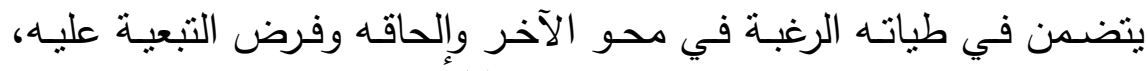

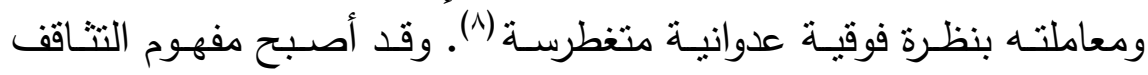
مصطلحاً مهماً لتفسير مختلف الظواهر المتعلقة بالاثيات والأقليات الثقافية الثية 
متل الهجرة الدولية، العولمة، الصراعات السياسية المنادية بالتعددية الثقافية

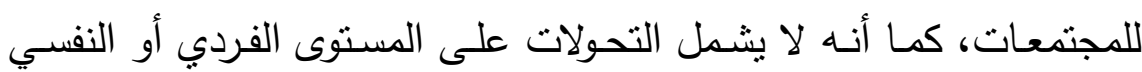
حسب بل كذلك على المستوى السوسيوتقافي، فالتحليل البنائي يهنت كثيرا

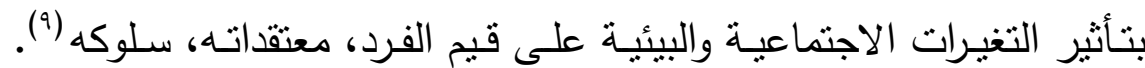

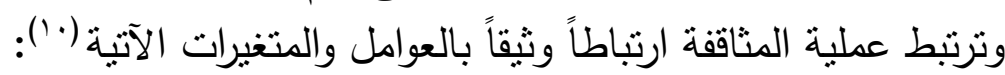

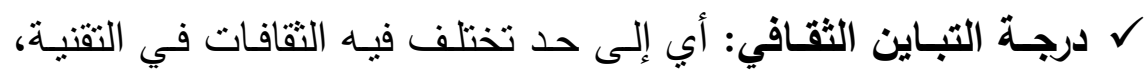

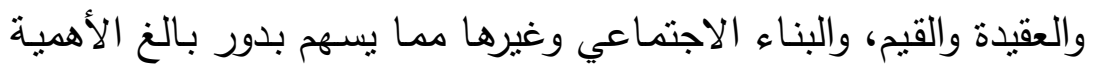
في عملية التثاقف. ل ظروف الاتصال وكثافته: إذ يكون الاتصال عدائياً أو ودياً، وقد ينطوي

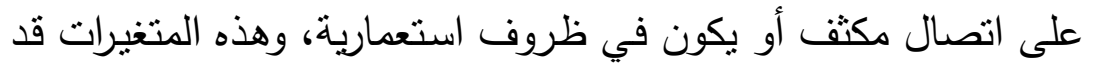

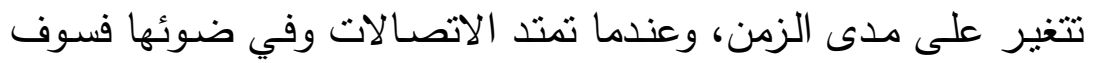
يتتوع التثاقف ويتباين. حواقف السيطرة وإلتبعية: فقد تكون الثقافة متكافئة، ولكن تتخذ إحداها

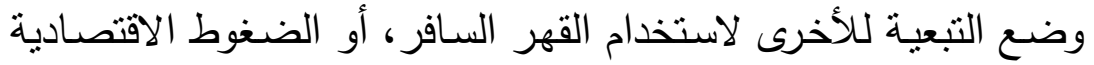

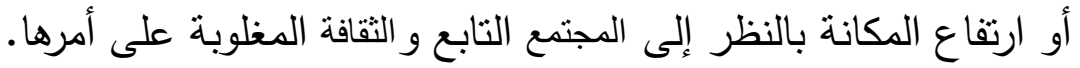

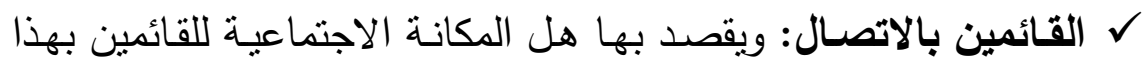

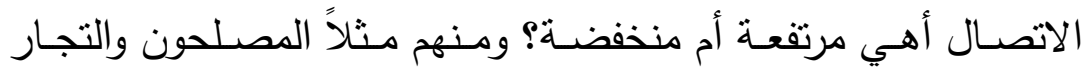

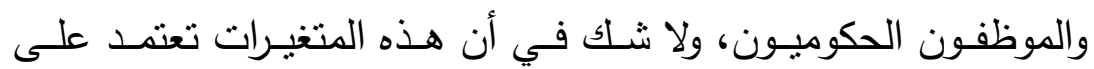
عنصر ظروف الاتصال وكثافته. ل اتجاه المد التأثيري: إذ هل بسير سيل التهيل الابتداعات الناتج من التثاقف

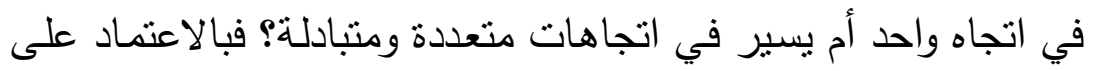

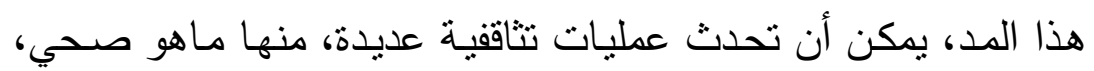

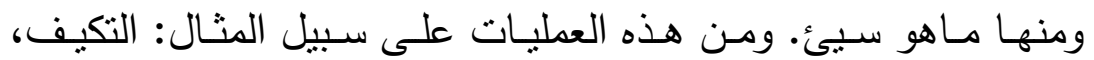

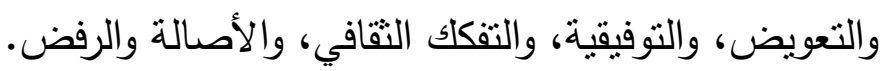
ويميز المؤرخون بين نوعين من المثقافة (') 
> المثاقفـة التلقائيـة: وتتـدرج في إطـار التلاقحات الناتجـة عن الحروب الناجمـة عن الرغبـة في الحصـول على العبيد أو الاتصـالات السـلمية

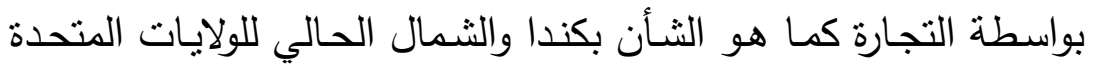
الأمريكية. المثقافة المفروضة: وتتنم عبر سبطرة الأوروبيين بصفة مباشرة وبالقوة على الهنود مثنلا، وذلك بعد هضم حقوقهم الاقتصادية والسياسية والمس

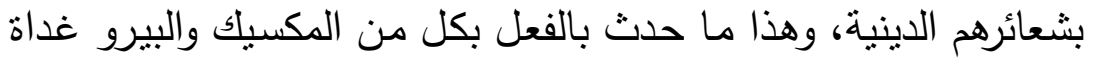
الاكتشافات الجغرافية الكبرى. أما من إذ مسارها ونتائجها فنتقسم المثاقفة إلى مستوبين (r')

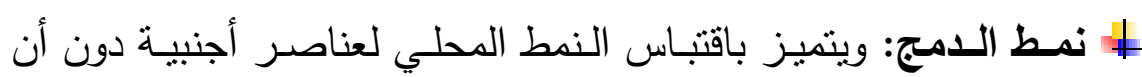
يؤدي ذلك إلى تغيير كبير في قيم التقافـة المحليـة، فقبائل النفاهوس (Navahos)، والتي كان سكانها نصف رحل، كانت تعتمد في عيشها على الصيد والالتقاط، وقد دفعها احتكاكها واتصالها بمراكز الاستيطان الإسباني إلى الاستقرار واعتماد الفلاحة، لكنها عادت ثانية إلى مزاولة ولنة تربية الماشية والماعز بعد أن اندمجت بقبائل أخرى ليصبح نمط عيشها الأثها الترحال من جديد، أما قبائل الكواكيوتيل (Kwakiutl) الموجودة بشمال اندمال

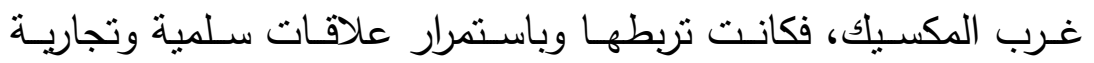

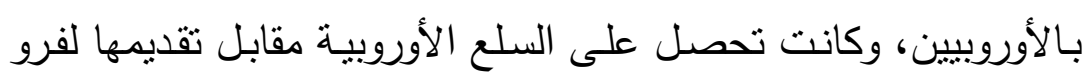
ثعالب الماء. وقد أدى الأمر إلى انتشار ظاهرتي المنافسة والمزايدة على ولى لإنى

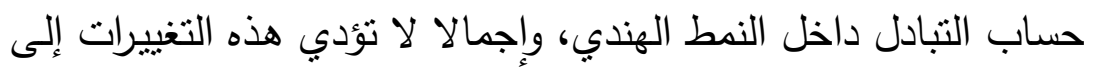
انهيار الثقافة المحلية. \# نمط التمثل: ويعني أن تشرب ثقافة الهنود لعناصر الثقافة الغربية يوازيه القضاء على التقاليد المحلية والانقياد لقيم المجتمع المسيطر . لمبرد 
أ- ألتثاقف والاستلاب

يعد مفهوم الاستلاب من المفاهيم الأكثر استعمالاً وتداولاً في خطابنا

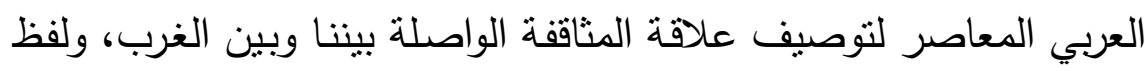

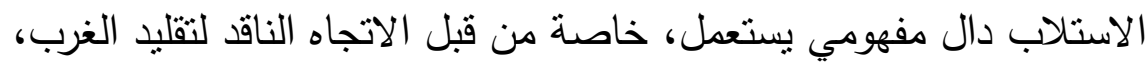

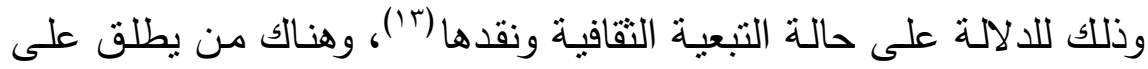

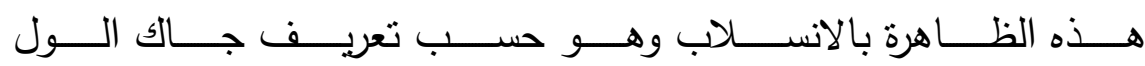
(1994-1912) Jacques Elulle الشخص عن نفسه ليصبح خاضعا وحتى متمثلا بشتص آخر ، في حالة نفسية تجعل الفرد يبتعد وينبذ نقافته لصالح ثقافة وافدة. وهنا ينطبق مفهوم الاستلاب على مفهوم التثاقف في شقه السلبي، إذ يصبح التثاقف وسيلة

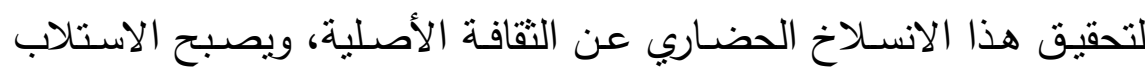

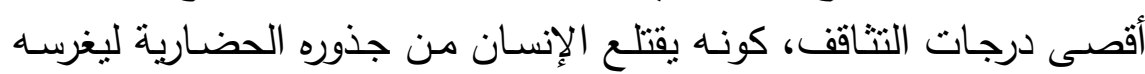
في بيئة حضارية أخرى. ب- التثاقف والاستيعاب

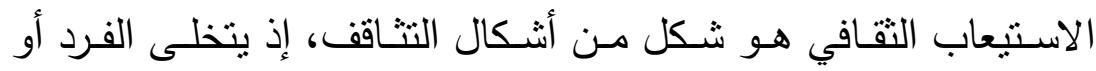

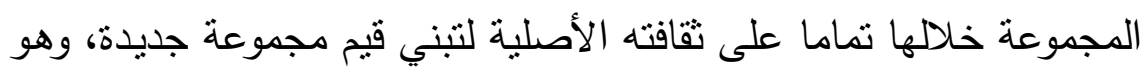
إحدى المراحل الممكنة لعملية التثاقف، كما يعد الاستيعاب المرحلة النهائية لعملية التثاقف، التي تتتهي باستبادل الفرد ثقافته وقيمه بثقافة وقيم أخرى.

ج- التثاقف والمناقلة الثقافية (Transculturation)

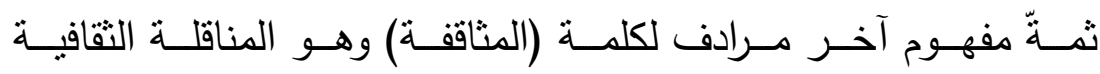
أي مجموعة التحولات المستمرة الخلاقة التي لا نتتهي (Transculturation)

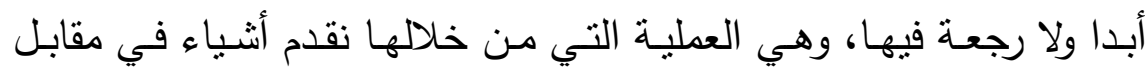
الأثياء التي نتلقاها، وهنا يحصل تعديل وتطور لطرفي المعادلة، وينتج عن وهن 
هذه العملية حقيقة جديدة ليست فيفسائية، وإنما ظاهرة جديدة تماما، أصلية

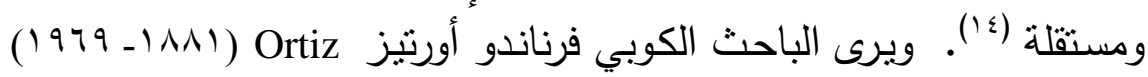

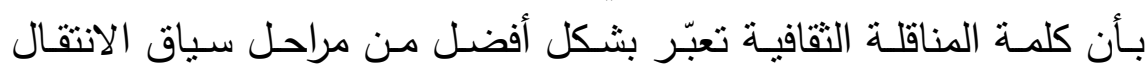

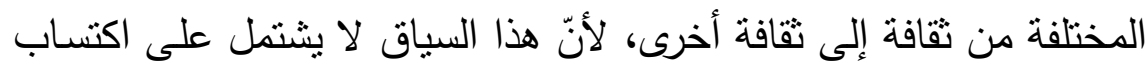

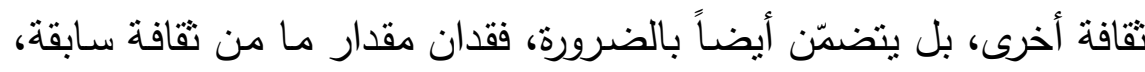

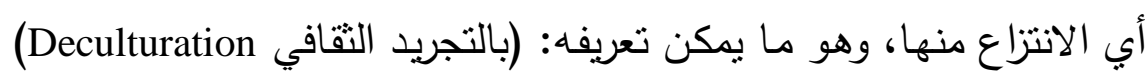
أضف إلى ذلك، أنّه يقود إلى فكرة ظاهرة نشأة ثقافة جديدة، وهو ما يمكن تُهن

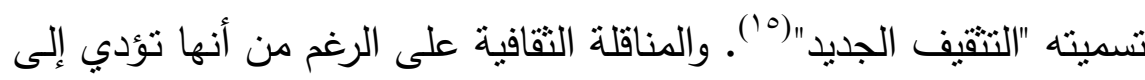

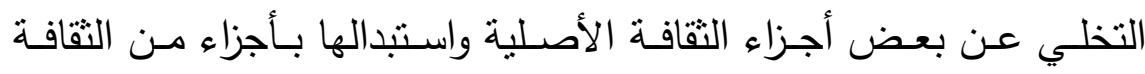
المكتسبة إلا أنها تسهم في بناء نمط ثقافي جديد أكثر تطوراً.

\section{د - التثاقف والنسبية الثقافية}

يعني مصطلح (النسبية الثقافية) عدمَ وجود قيم شاملة لجميع البشر ، اذ أن كل ثقافة تعبر تعبيرا متميزا عن الثعوب والأمم التي تثؤمن بها، وتبرمج

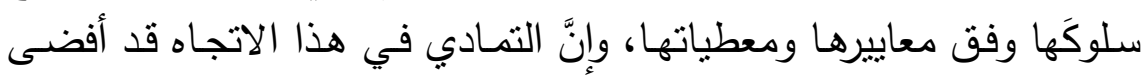

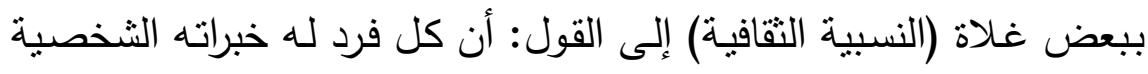

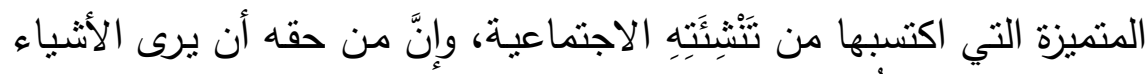

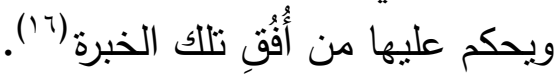

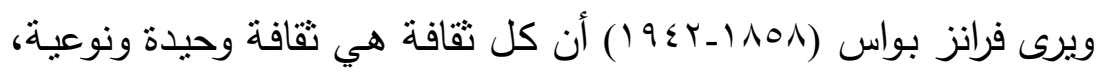

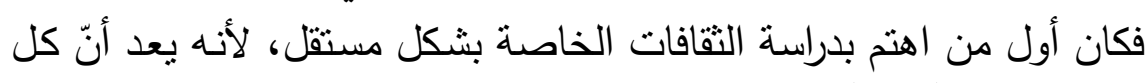

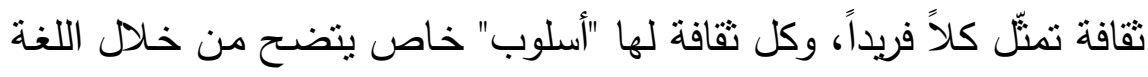

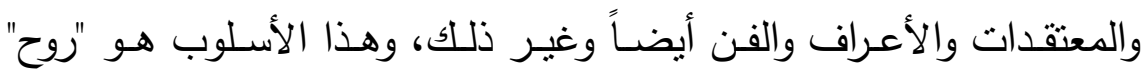

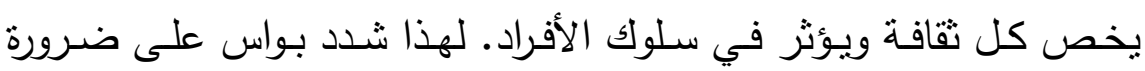
احترام النسبية الثقافية وإعطاء قيمة لكل ثقافة ونادى بالاحترام والتسامح إزاء 
الثقافات المختلفة، وطالما أن كل ثقافة تعبّر بشكل خاص عن كون الإنسان

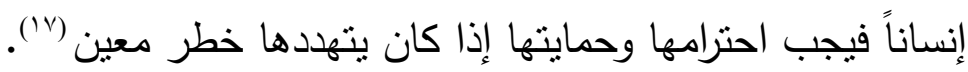
وعلى الرغم من الاحتكاك الدائم بين مختلف الثقافات والذي تسعى من إنان

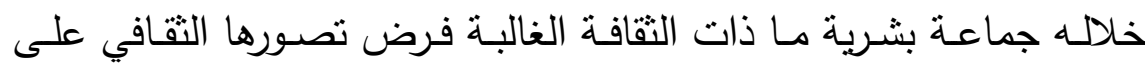

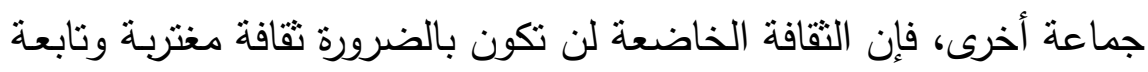

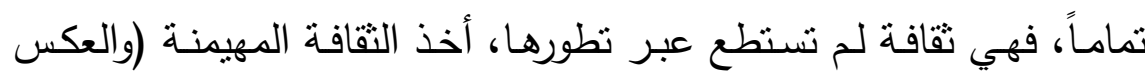

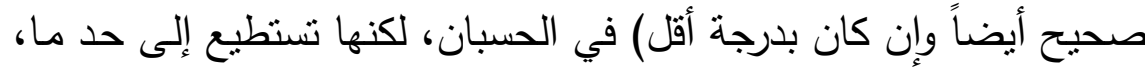

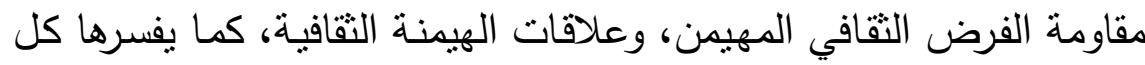

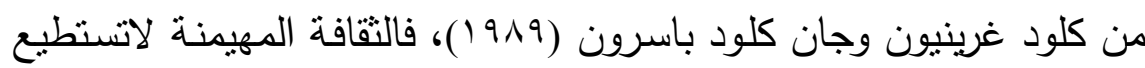

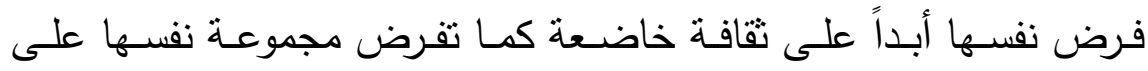

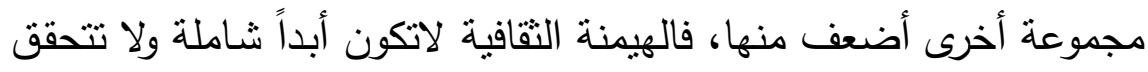

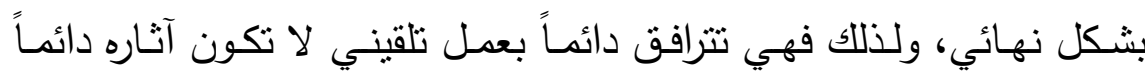

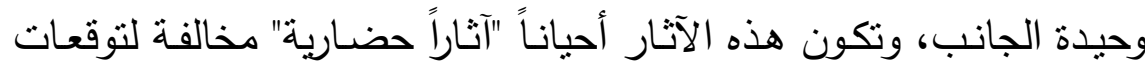

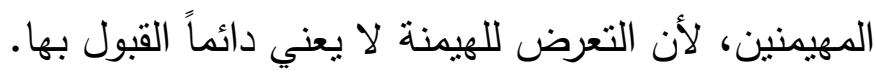

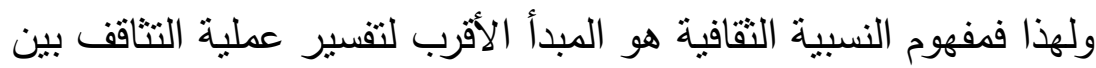

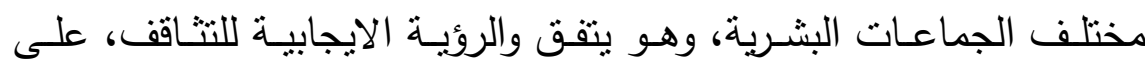

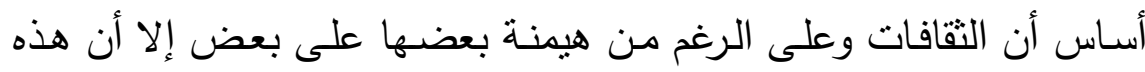

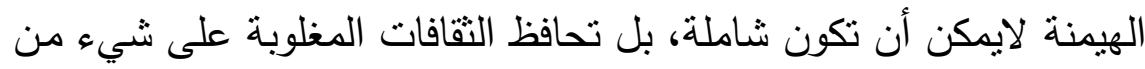

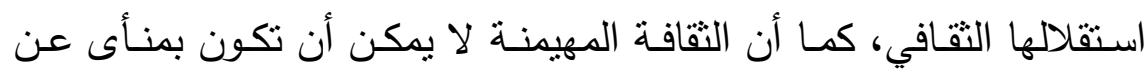
التأثر بقيم الثقافة المغلوبة، وهذه هي سنة الثنافة التثاقف الكونية. ثانياً: شبكات التواصل الاجتماعية وفرص التحول الايمقراطي

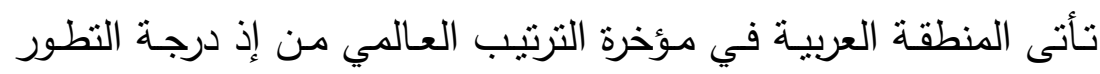

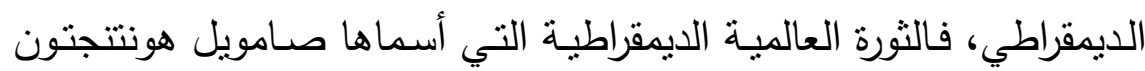

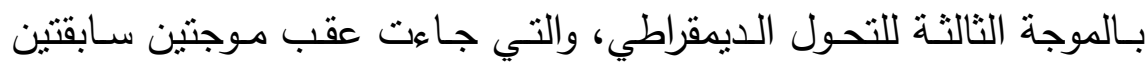




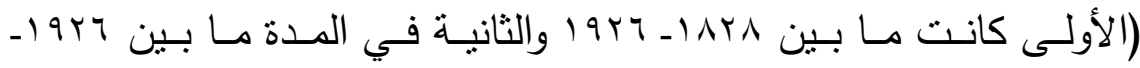

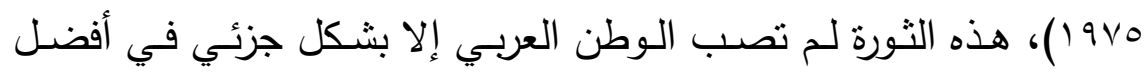

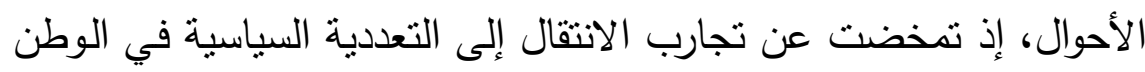

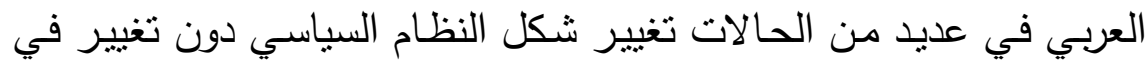

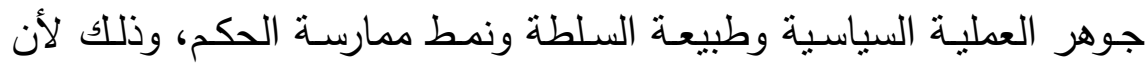

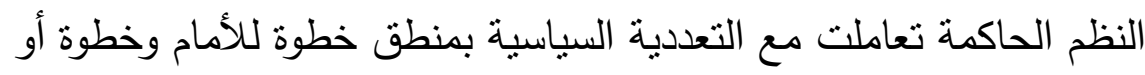

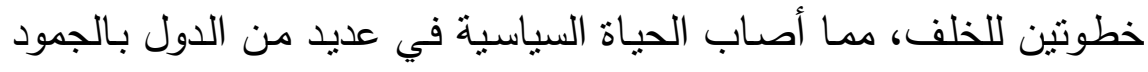

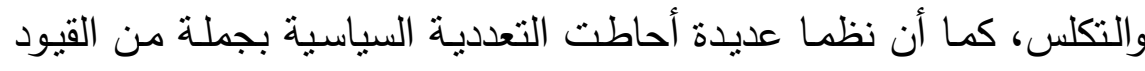

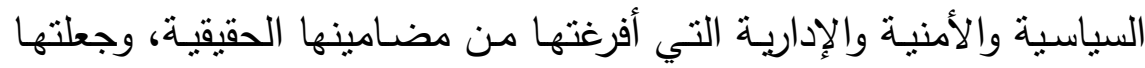

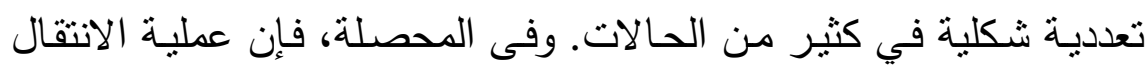

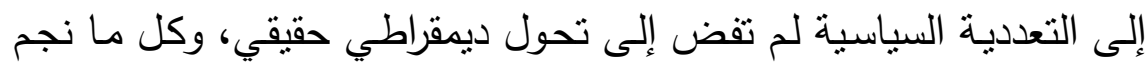

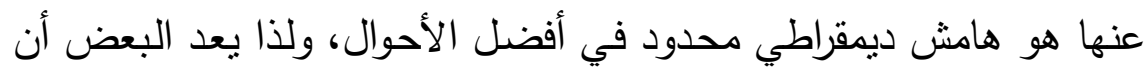

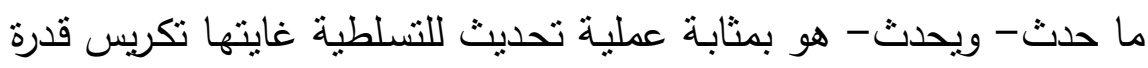

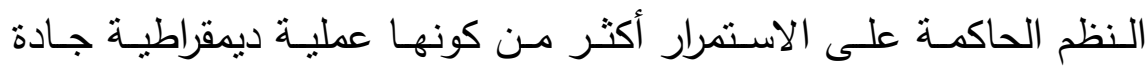

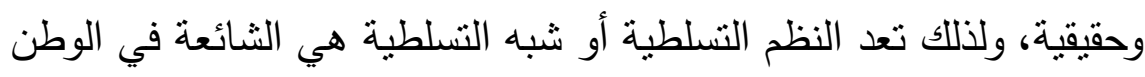

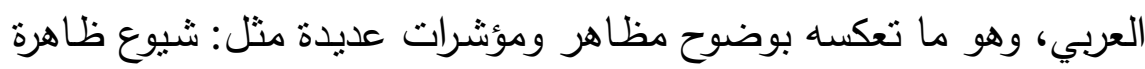

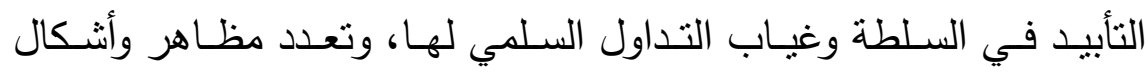

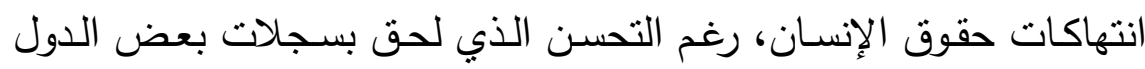

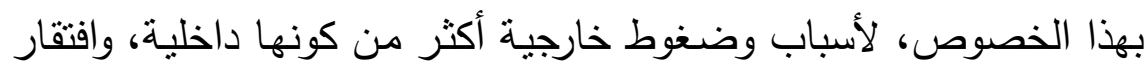

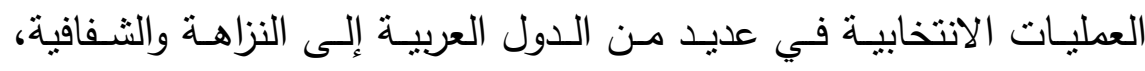

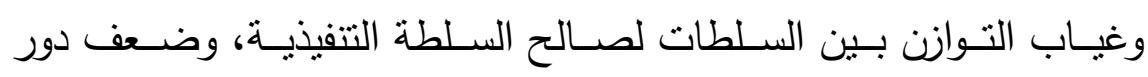

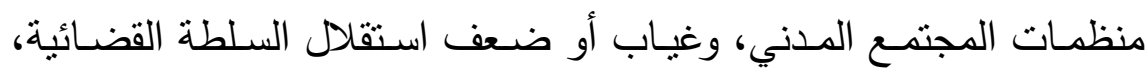

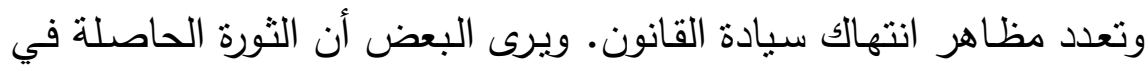

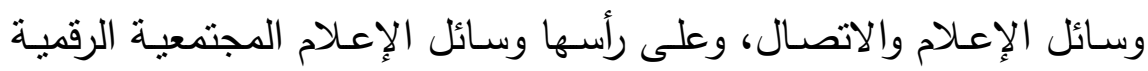
يمكن أن نسهم في تفكيك الأفكار والبني السياسية والاجتماعية المرتبطة الإنة 
بالتسلطية من ناحية، ودعم عملية التحول الديمقراطي في المنطقة العربية

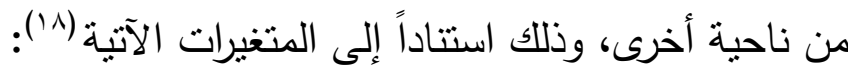

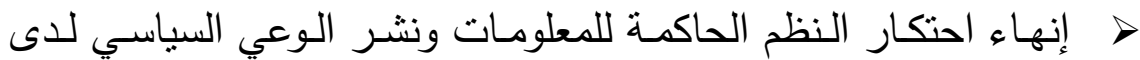

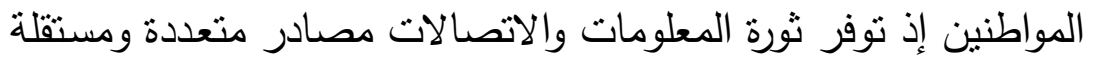

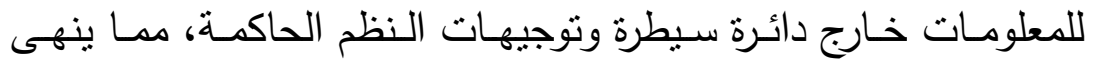

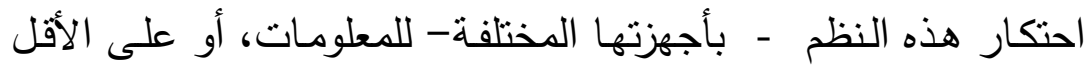

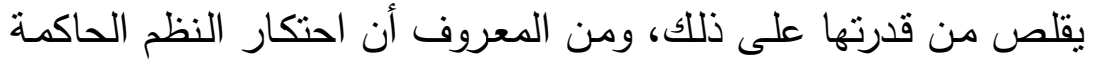

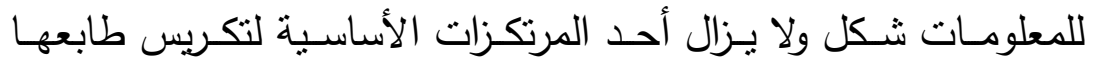
التسلطي. > كما أن هذه الثورة تحد من قدرة النظم الحاكمة على إخفاء ممارساتها

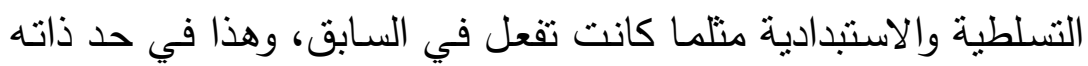

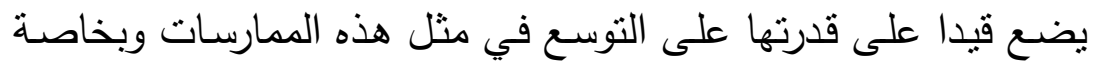

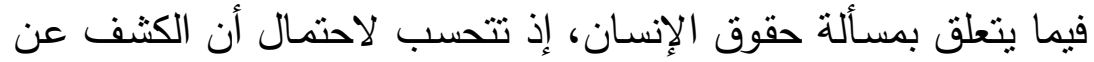

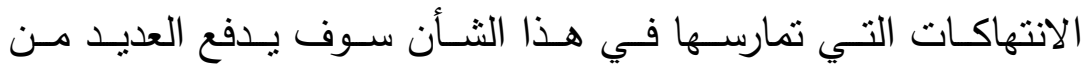

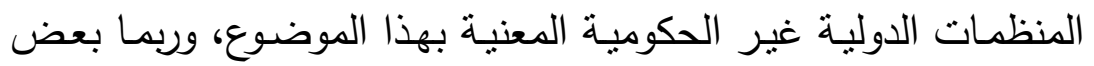

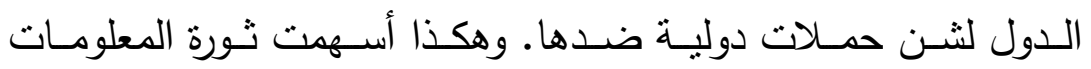

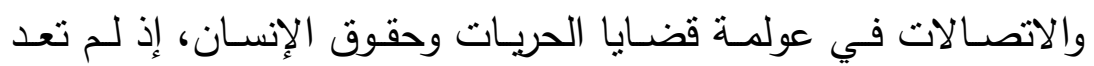

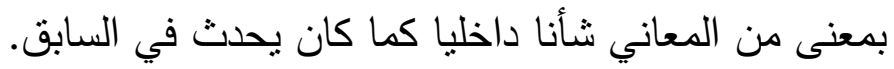

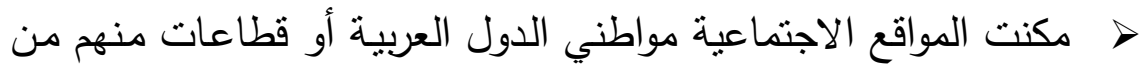

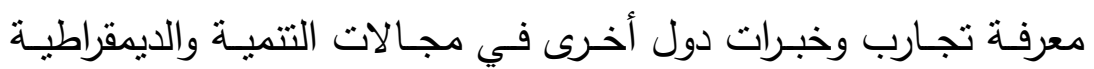

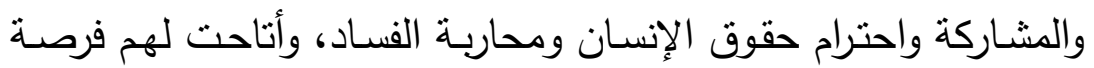

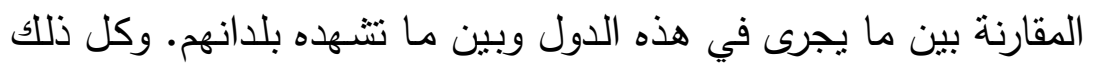

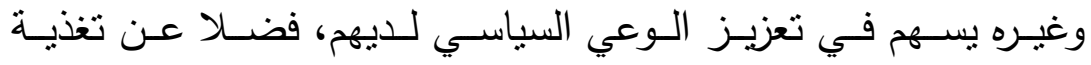

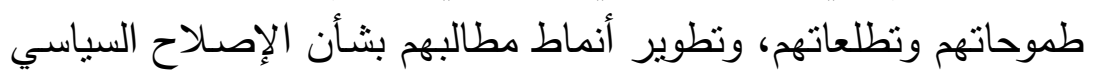
والديمقراطي. 
> يمكن أن تسهم المواقع الاجتماعية الرقمية في تعزيز دور أحزاب وقوى

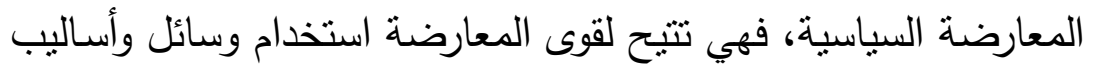
جديدة لنشر أفكارها وبرامجها، وممارسـة أنشطتها، واستقطاب أعضـاء

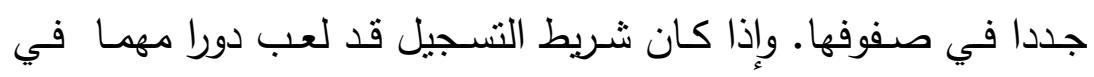

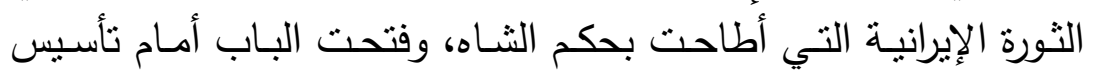
جمهورية إسلامية في إيران، وذلك من خلال نشر خطب الإمام الخميني

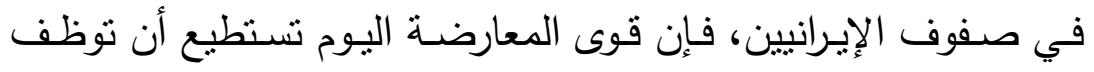

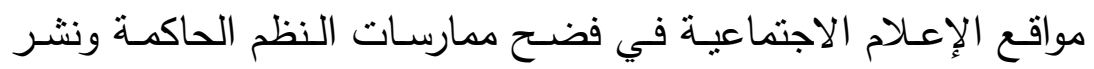

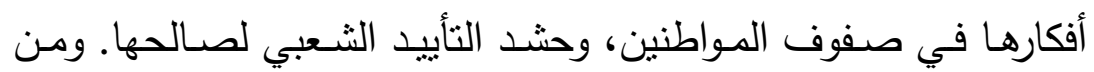
الملاحظ أن قوى المعارضة المحظورة داخل بعض الدول العربية، والتي تمارس المعارضـة من الخـارج كثيراً ما استفادت من الأسـاليب الحديثة في الاتصالات والمعلومات في التواصل مع المواطنين داخل أوطانها.

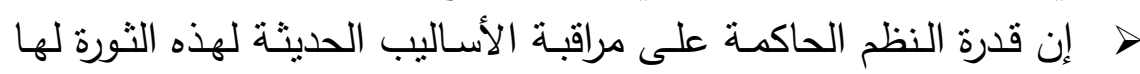

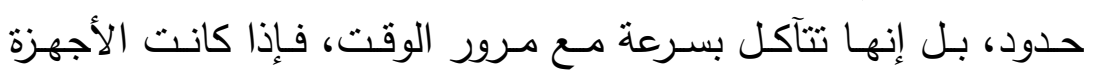

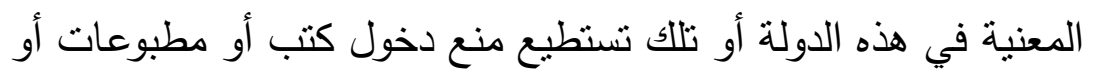

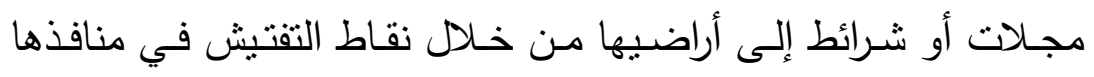

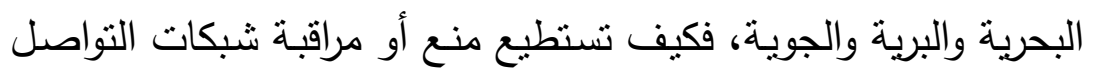

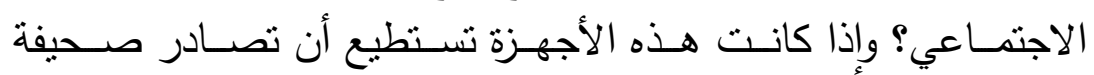

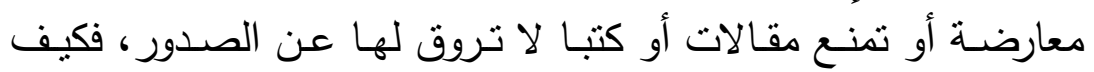

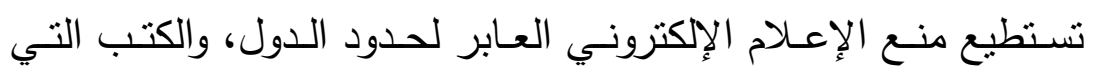
تصدر بشكل إلكتروني (النشر الإلكتروني) على شبكة الإنترنت؟ وإن إنت كانت بعض النظم تسنطيع الآن أن نراقب شبكة الإنترنت بشكل جزئي بأن تتدخل تقنيا لحجب بعض المواقع غير المرغوب فيها، فإن هناك شكوكاً بشأن قدرتها على الاستمرار في هذا المسلك في المستقبل. 
دراسات إقليمية 9 ( 9 (r)

وهكذا، فإن ثورة المعلومات والاتصـالات توفر وسائل تسمح بالبث

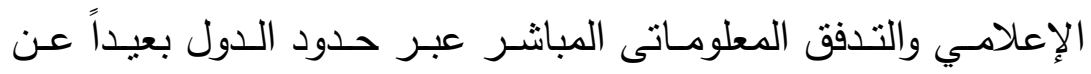

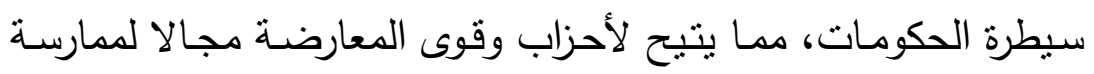

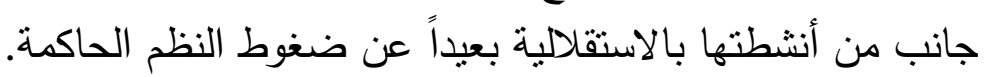

ثالثاً: شبكات التواصل الاجتماعيـة وتأثيرهـا في هويـة المـواطن

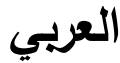

تعرف التقافة على أنها عبارة عن مجموع الأفكار والعقائد والدفاهيم

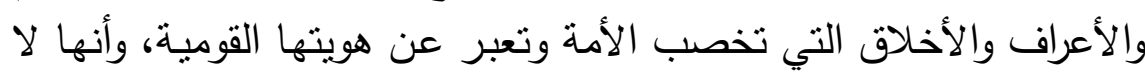

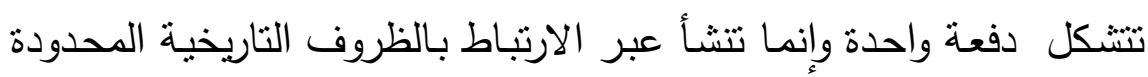

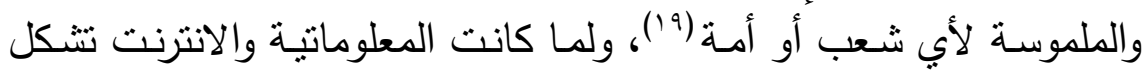

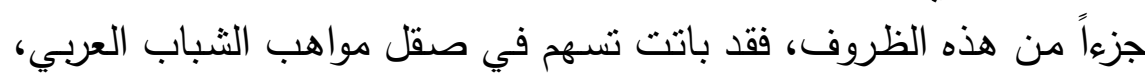

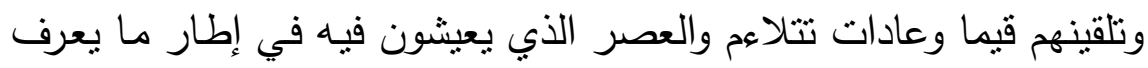

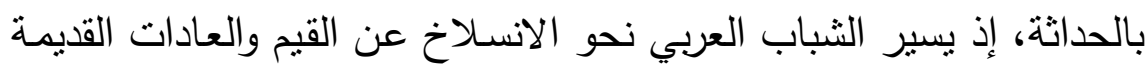

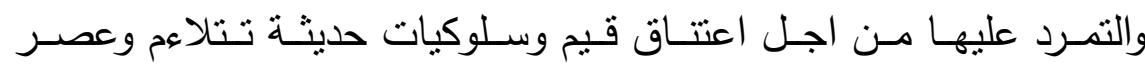

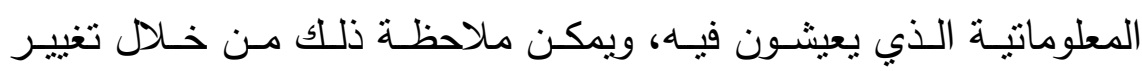

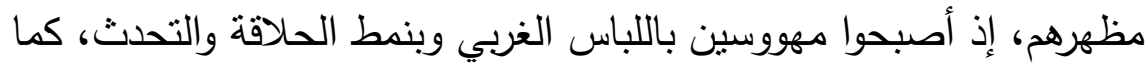

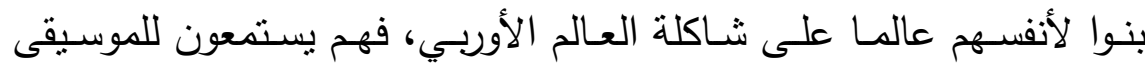

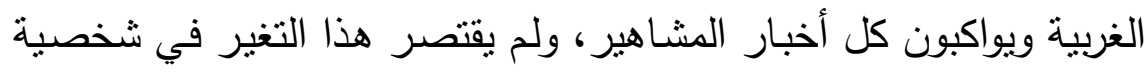

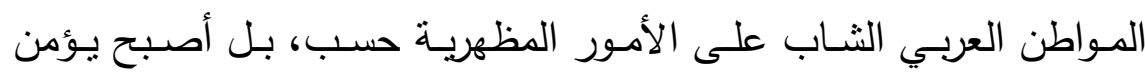

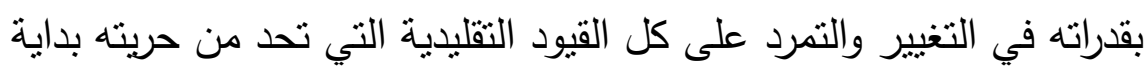

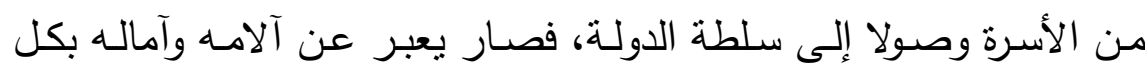

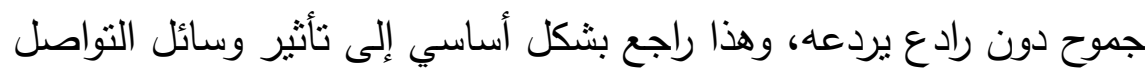

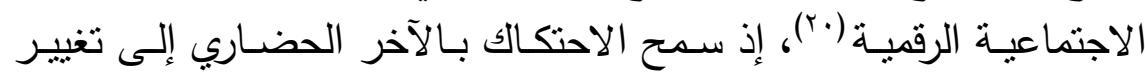


النمط الفكري لدى الثاب العربي البسيط فصارت وسال الإعلام الاجتماعية احد العوامل المتدخلة في تكوين التشئة السياسية للمواطن العربي، بعدما كانت تقتصر على الأسرة والمدرسـة ووسائل الإعلام الوطنية المحتكرة من قبل النظام الديكتاتوري العربي، وشكلت مواقع التواصل الاجتماعي منتفسا

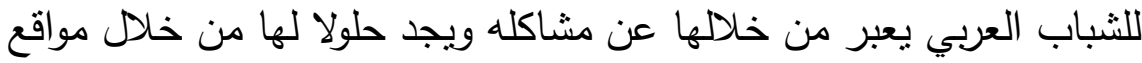

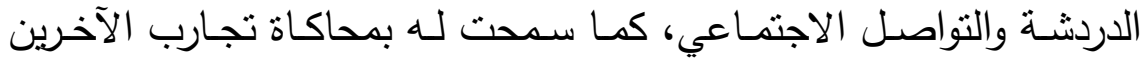
والتشبع بقيم الحربة والعدالة والديمقراطية والمشـاركة التي ينعم بها المواطن الغربي·

ولعبـت البيئة الدوليـة الحالية دور في انتثـار الثبكات الاجتماعيـة في

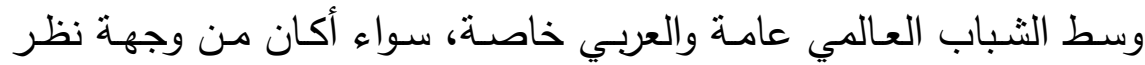
اجتماعية أو تكنولوجية معا، فسوق الانترنت هي في توسع مستمر تسمح

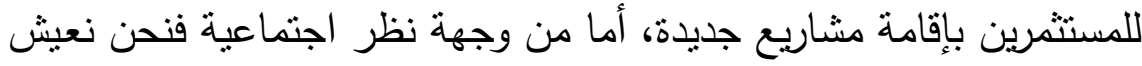

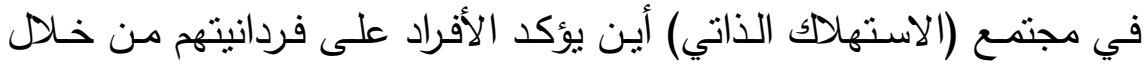

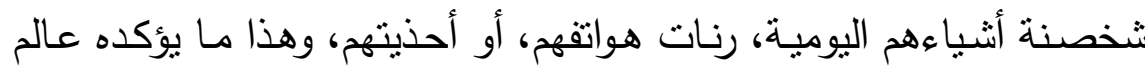

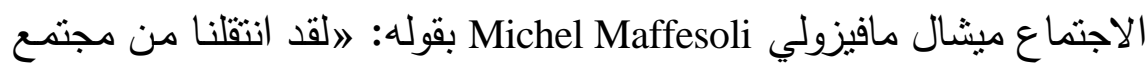
جماعي إلى مجتمع فرداني، وتوكيد ضرورة التميز عن الآخرين وأخذ خياراته

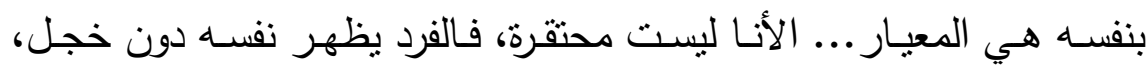

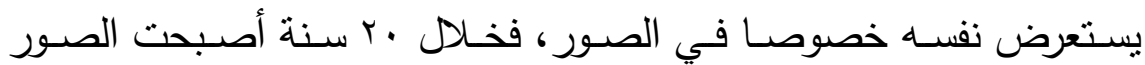
الذاتية ذات أهمية كبيرة خاصة مع غزو الرقمنة (اr)" . ومن هذا المنطلق أصبحت شبكات التواصل الاجتماعيـة تمنثل تهديداً

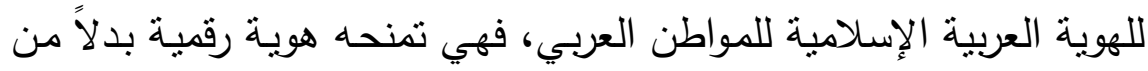
هويته الأصلية إذ يستبدل اسمه باسم المستخدم الالكتروني، ويشـل وقته فئه

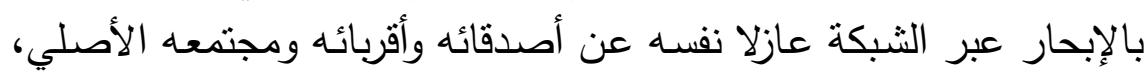

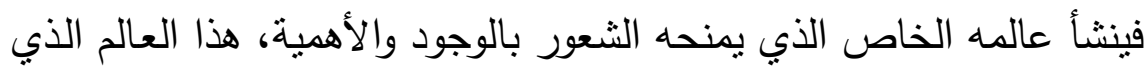

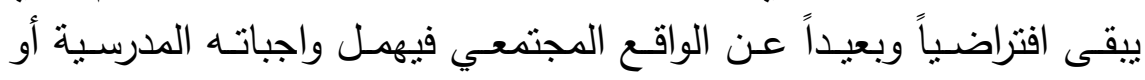


المهنيـة وينشـخل بـالجري وراء الأوهـام التي يوفرهـا لـه الموقـع الاجتمـاعي،

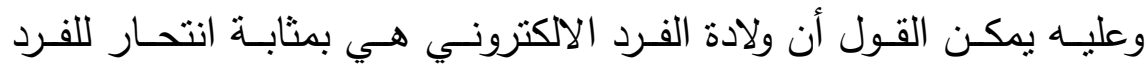

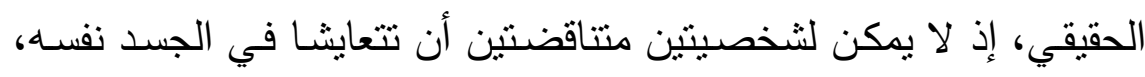
لذا يصبح الفرد أمام خيار التخلي عن إحدى الشخصيتين وتقمص الأخرى،

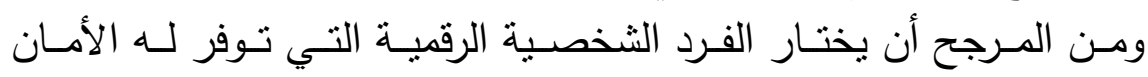

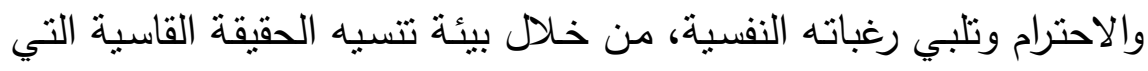
يعيشها في العالم الحقيقي من فقر وبطالة وتدني مستوى المعيشّة والظروف

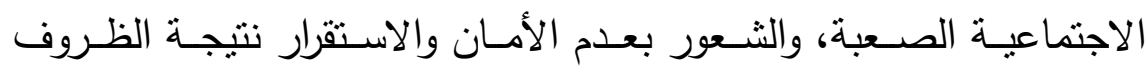
السياسية غير المستقرة في العالم العربي، فتنكل المواقع الاجتماعية بديلاً

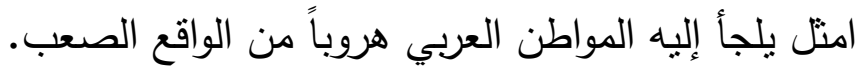

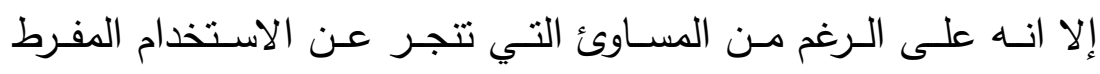

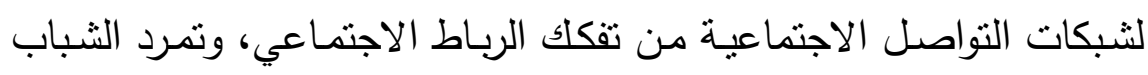

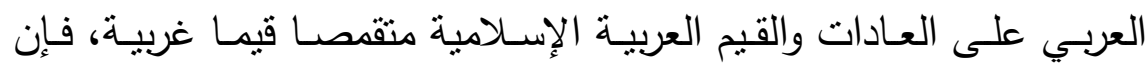

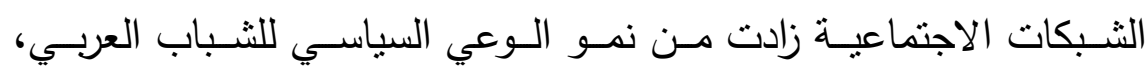

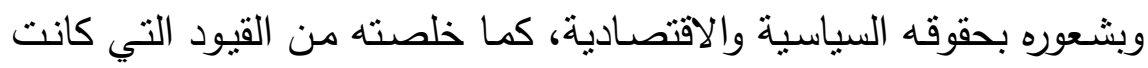

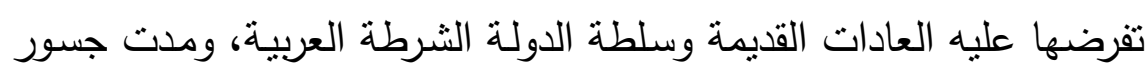

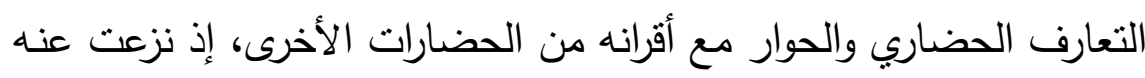

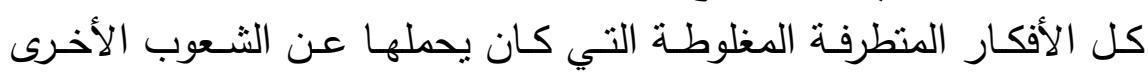

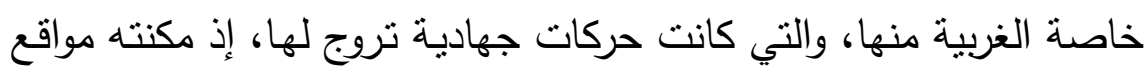

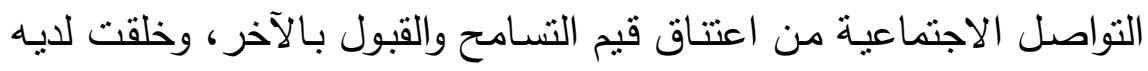
فضولا في معرفة الآخر والاطلاع على نمط معيشته وأسس حضارته.

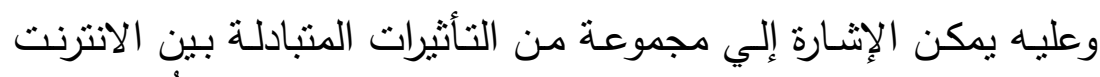

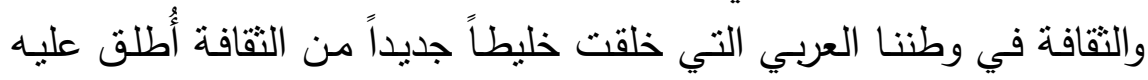
"ثقافة دوت كوم"، أهمها ما يأتي (rr): 
هـ اضدحلال دور مؤسسـات التشـئة التقليديـة في تشكيل ثقافـة الثباب،

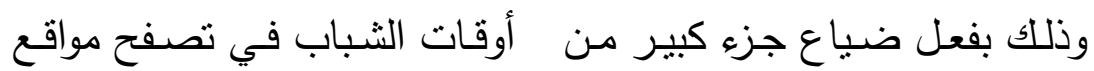
الانترنت والمشـاركة في المجمعـات الحواريـة ومجموعات الفيس بوك،

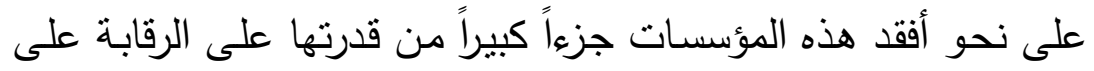

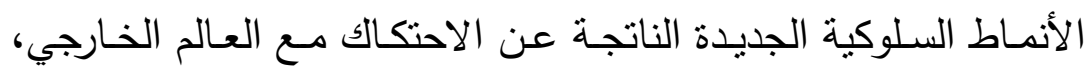

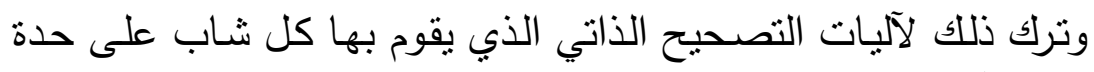

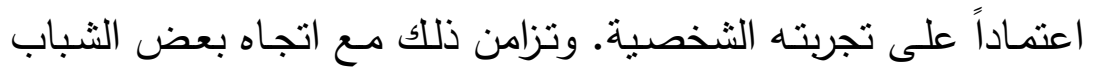
إلى الانعزال عن مجتمعاتهم، والانكفاء خلف جهاز حاسب آلي يمثنل أداة الاتصال الأساسية إن لم تكن الوحيدة مع العالم الخارجي.

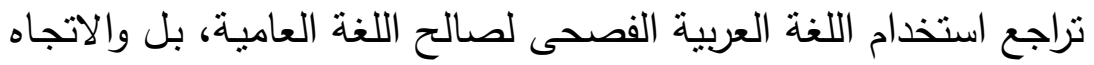

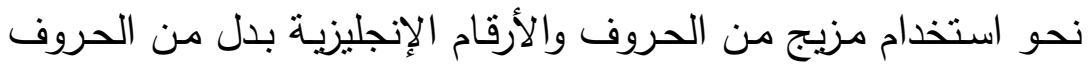

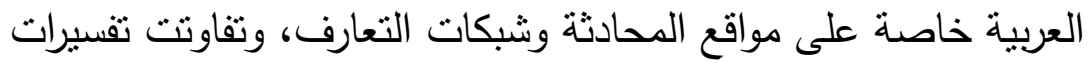
المختصين حول انتشار هذه الظاهرة، ففي حين أرجع د. على صلى صلاح

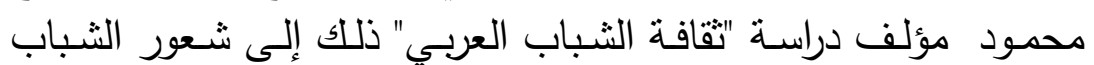

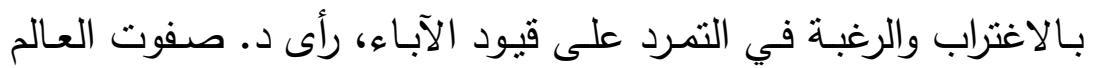

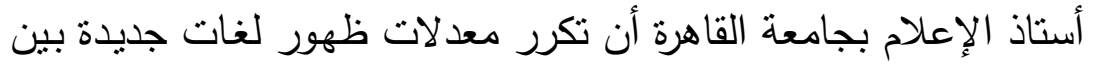

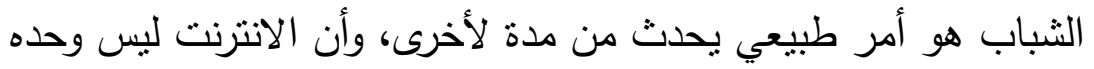

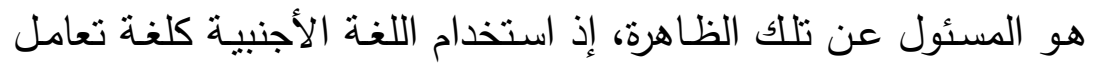
في بعض أماكن العمل وتردي التعليم.

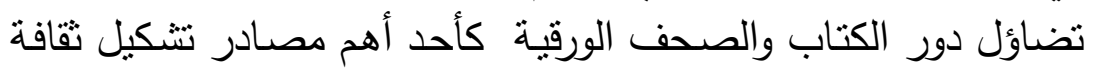

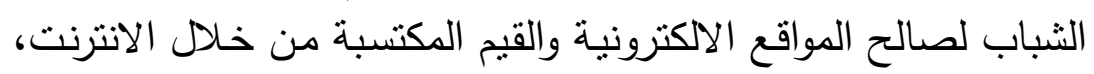

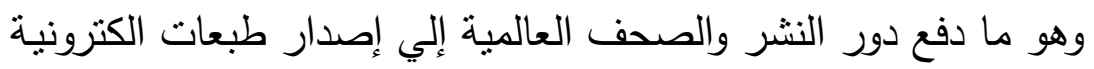

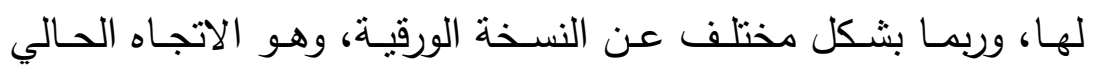
لمعظم دور النشر والصحافة العربية، وإن كان لم يصل إلى درجة تقديم نسخ مغايرة لما هو منشور ورقياً . 
تعميق شـور الحيرة ما بين المحلي والعالمي، فنتيجة للانفتاح الهائل

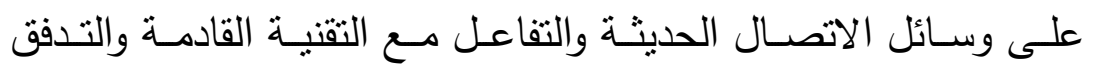

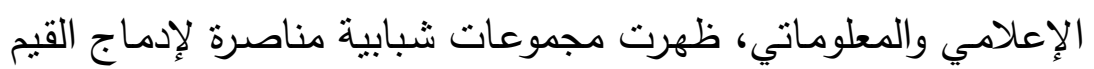

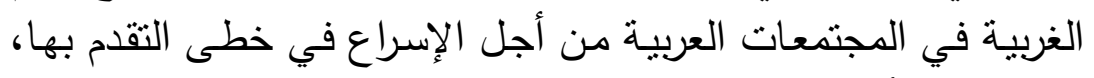

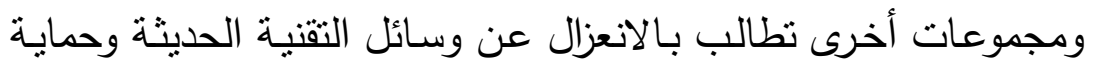

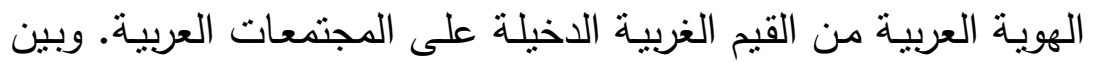

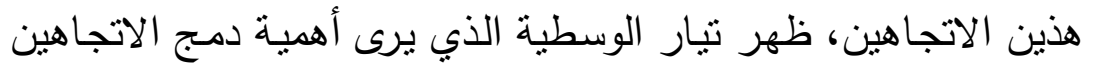

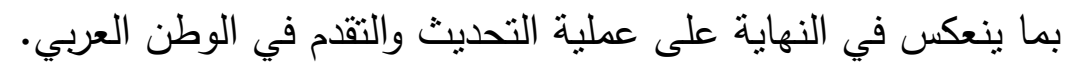

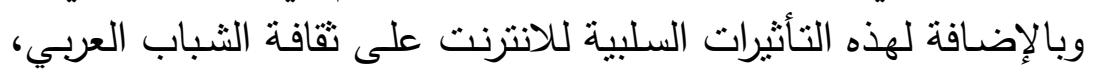

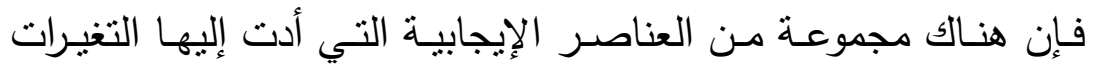

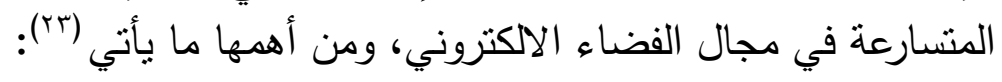

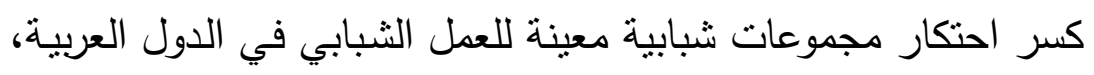

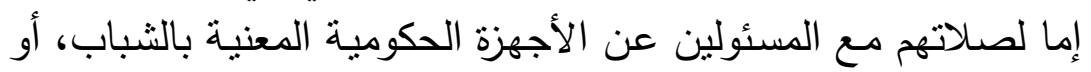

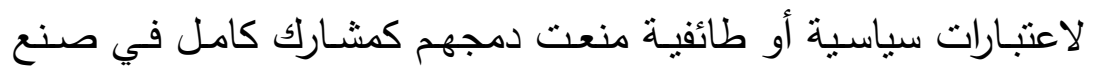

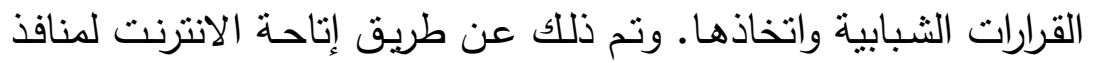

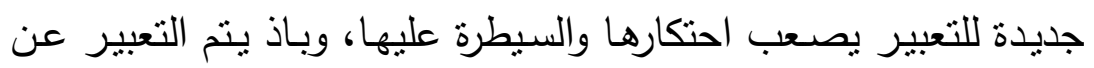
جميع أصوات الثباب في إطار ديمقراطي.

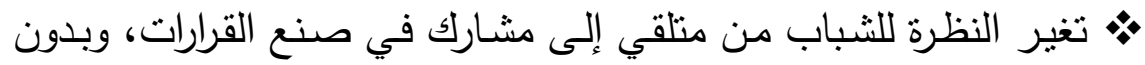

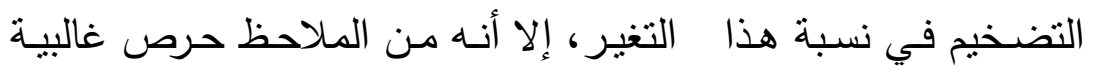

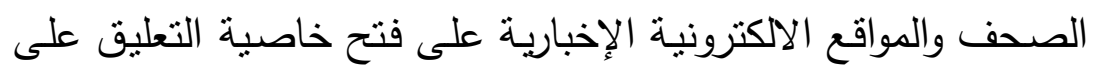

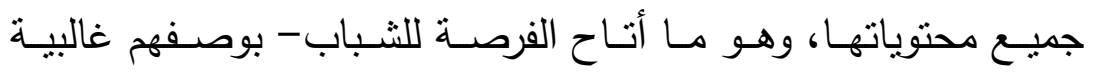

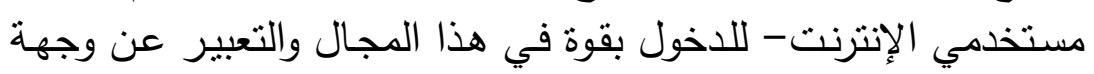
نظرهم تجاه القضايا المثارة وطريقة التعامل الحكومي معها.

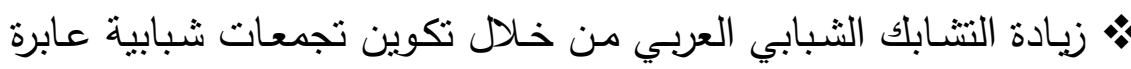

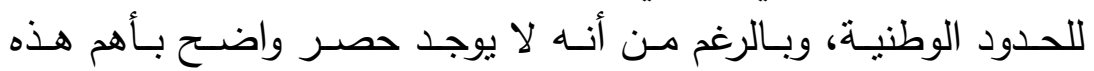

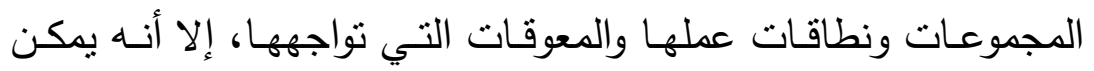


الحديث عن عدة مجموعات شبابية نشطة في هذا المجال منها مجموعة

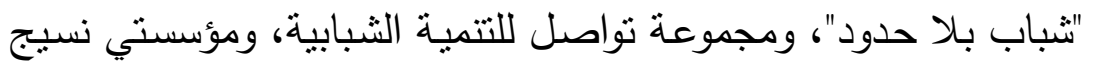

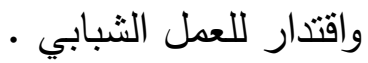
• بدء الانفتاح على الثبكات الدولية النشطة في مجال الثباب، وأهمها

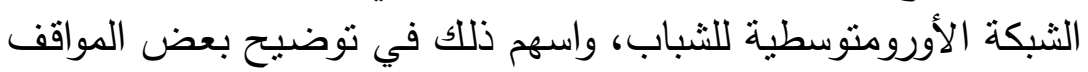

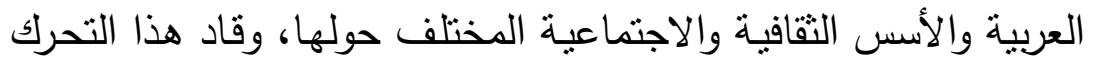

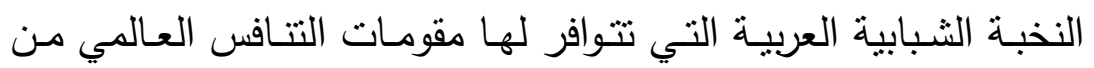
خبرات ميدانية وتعليمية متميزة.

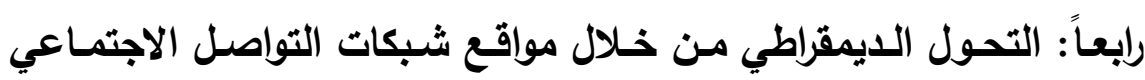

التجرية المصرية والتونسية أنموذجا

برهنت حركات شباب الثورة في كل من تونس ومصر عن الدور الفعال

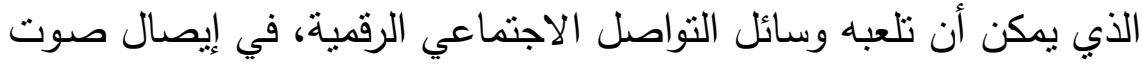

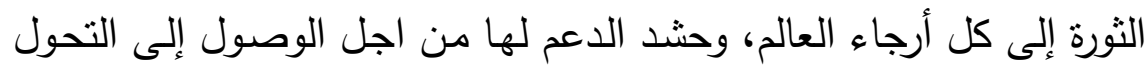

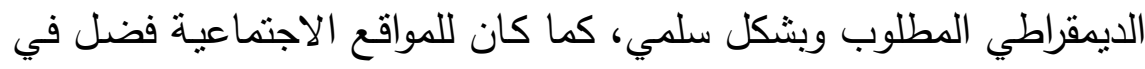
تعبئة الرأي العالم الشعبي الثبابي بشكل خاص، من اجل تتظيم المظاهرات

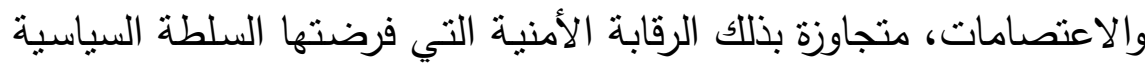
على كل وسـائل الإعـلام والاتصـال التقليديـة، ويمكن الوقـوف على لإنى دور الثبكات الاجتماعية من خلال التجربتين الآتيتين:

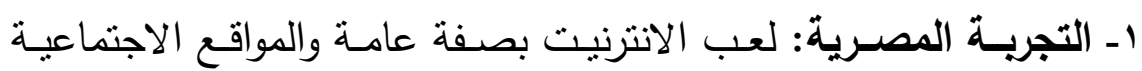

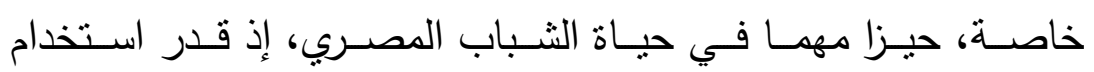

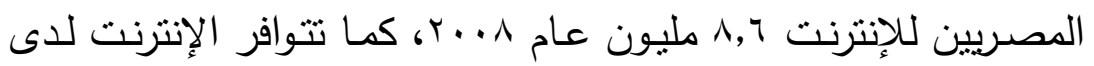

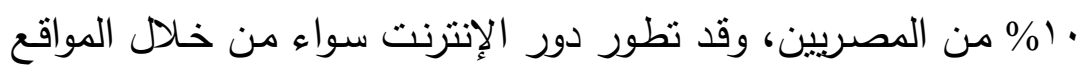

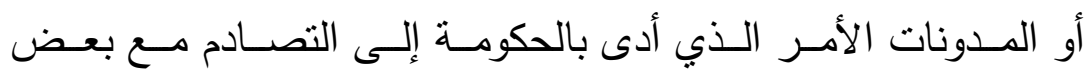

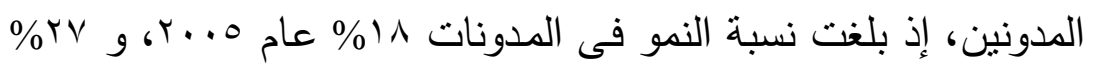

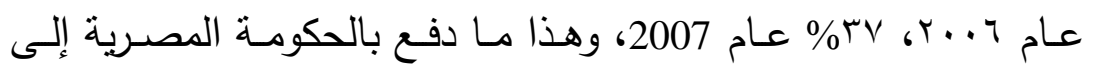




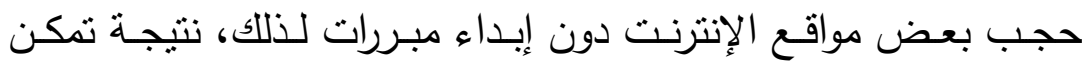

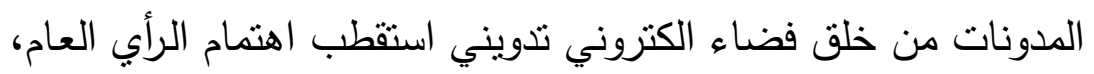

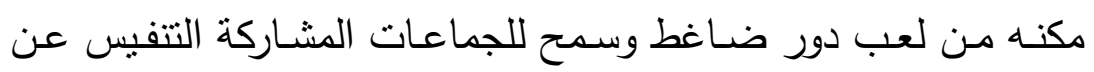

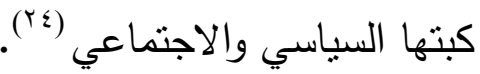

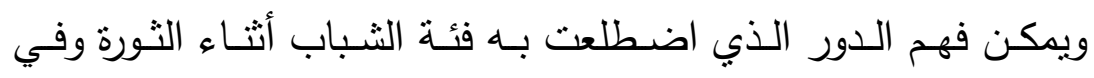
أعقابها، وموقف رموز النظام منها من خلال ما يسميه المؤرخ الهندي اهي راناجيت جوها Ranajit Guha "التحيز النخبوي" (ro)، إذ يفسر تجاهل مونل نائب الرئيس السابق عمر سليمان مطالب المتظاهرين، من خلال روئية فحواها أن المتظاهرين لا يمتلكون أيّ ثقافة أو وعي سياسي، ولائ يعدو

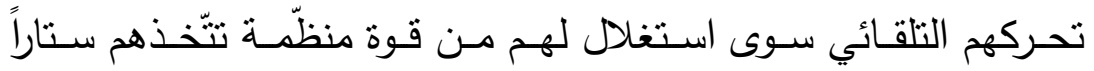

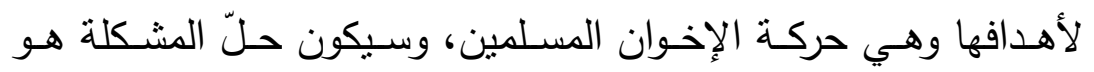

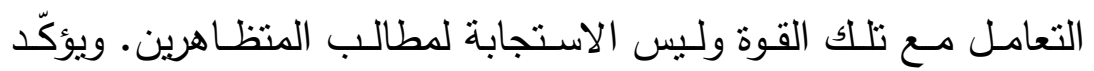
راناجيت جوها أنّ التّحيز النخبوي يستلهم الخبرات الغربيـة في الحركة السياسية، ويقفز فوق خصوصسية الواقـع المحلّي، ففي المثنال الهندي لئي

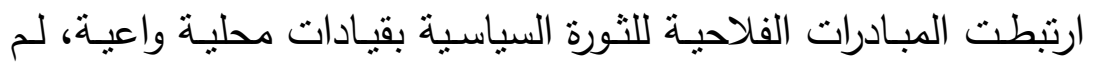
يكن أيّ منها يحكم سيطرته على العناصر الثورية كافة، بل اتّحدت هذه

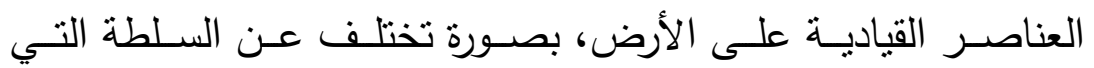
يمارسها التتظيم أو الحزب السياسي الحديث، وهذا ما تجسد خلال التورة

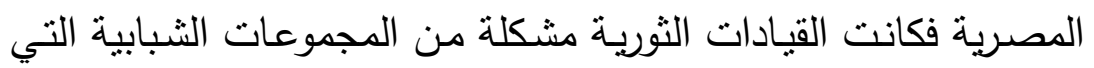
حملت الثورة المصرية على أكتافها، مثل حركة ج أبريل وحركة كفاية، وشباب الإخوان، والحملة الوطنية لدعم البرادعي، وحركة الاشـتراكيين

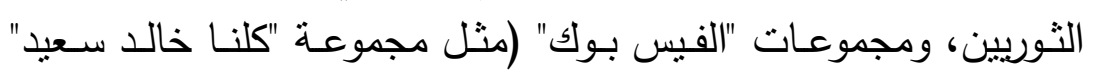
ومجموعة الرصد). ومن أبرز سمات هذه المجموعات الثبابية، التتوع

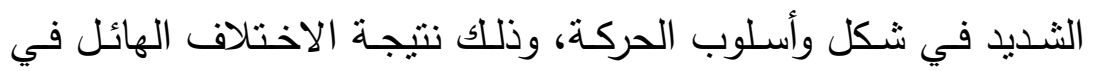
الخلفيـة الفكريـة والتتظيميـة للمجموعـات الثبابية، وتتســ أيضـاً بالقدرة 
الهائلـة على التواصل عبْر الامتداد الثبكي، وهو مـا لا يجعل لحركة الثورة مركزاً يمكن شل فاعليته أو قيادة يمكن استنئصال عناصرها، نظرا

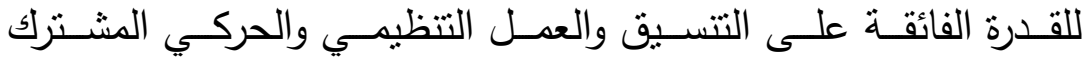
للمجموعات الثبابية، منلمـا اثّضـح من إطلاق فكرة النزول إلى الثـارع

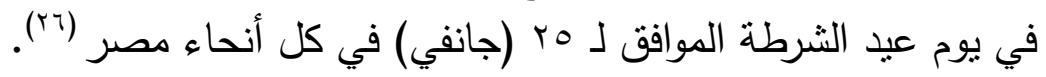
r- التجربـة التونسية: اندلعت الثورة في تونس بسلسلة من المظاهرات في

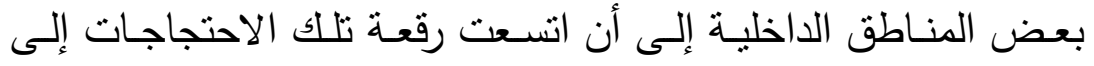

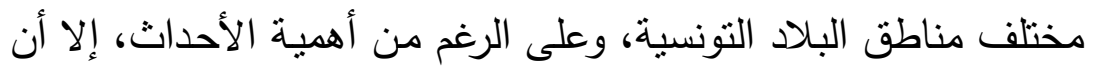

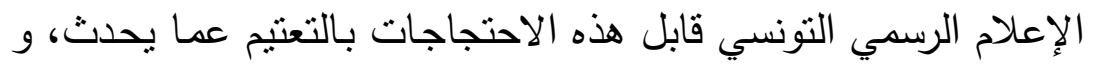
ذللك بالتضبيق على الصحافيين التونسيين والأجانب ومنعهم من تغطية

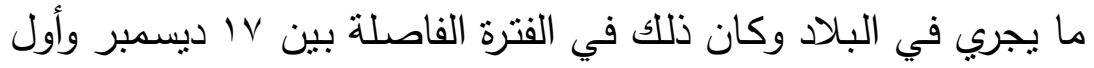

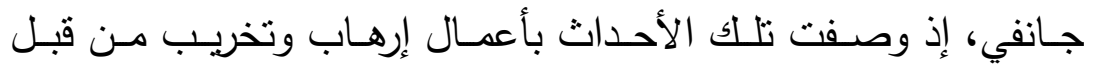
مجموعات "ملثمة. ونتيجة القمع و التضبيق الإعلامي الذي كان يعيشـه

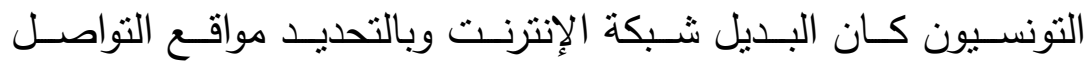

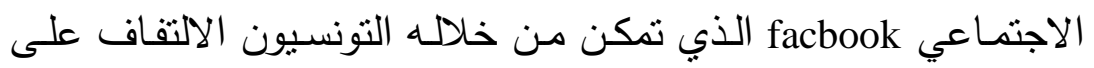
الرقابة والتعتيم الإعلامي. فقد نهجت أجهزة الحكومة ابان حكم بن علي

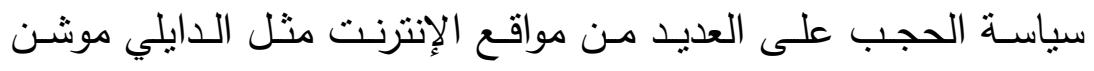
الإئم Dailymotion

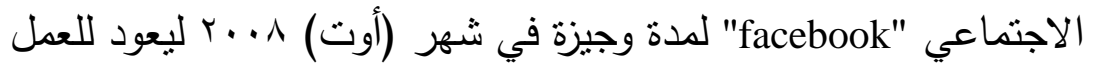

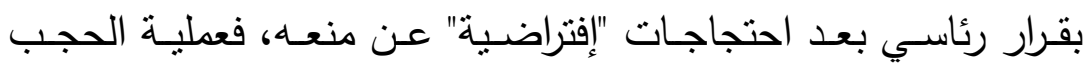

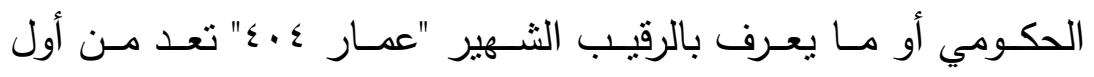
الاحتجاجـات "الافتراضية" عبر المدونات والمجموعات المناهضـة لهذا الحجب الإلكتروني عبر الفايسبوك مثل : "نهار على عمار"، "صفحة

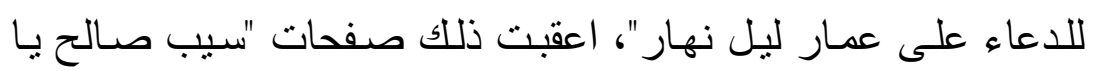


وعلى الرغم من كل هذه التضييقات الهادفة لتغطية الحقائق الميدانيـة فقد شكلت مجموعات و صفحات على facebook مثل صفحة "أخبار تونس"،

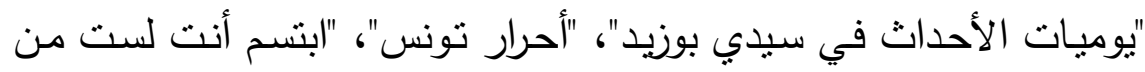

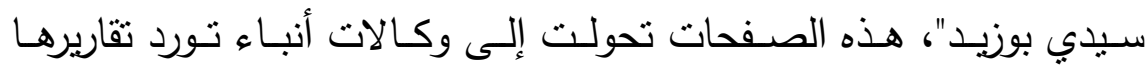
بالصوت والصورة اعتماداً على أجهزة و وسائل التكنولوجيا من تتاقل الوقائع والأحداث، فصارت وسائل الإعلام العربية والأجنبية من أبرزها قناة الجزيرة

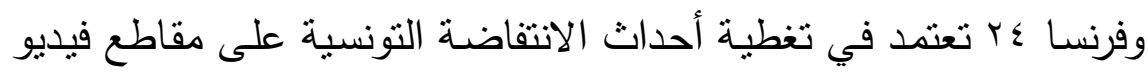

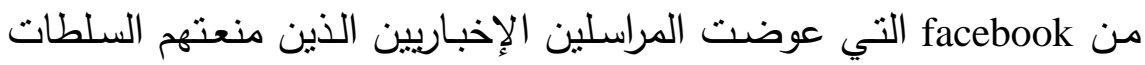
التونسية من تغطية الاحتجاجات وضيقت عليهم إعلاميا (^^). وخلال أيام الانتفاضة التونسية كان الربط بين وسائل الإعلام "الجديد

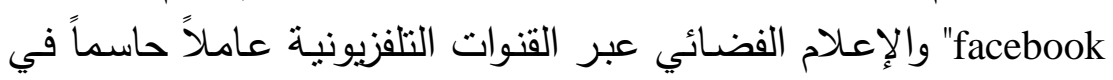
الحفاظ على زخم النضـال من اجل تحقيق التورة، إذ لعبت شبكة التلفزيون

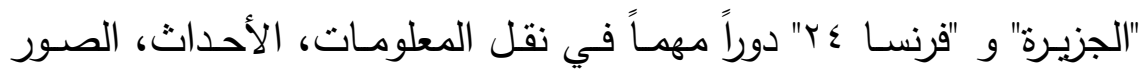
والفيديوهات إلى أكبر شريحة من المجتمع خصوصـاً الذي لا يتقن استعمال

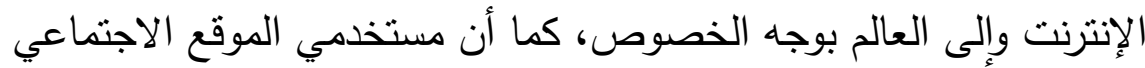

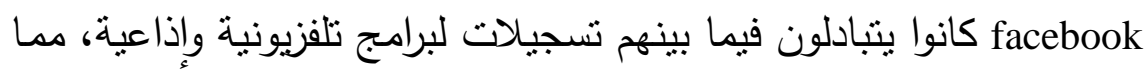

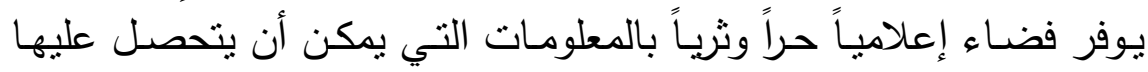
مستعمل facebook بسهولة وحينية وبتكلفة قليلة.

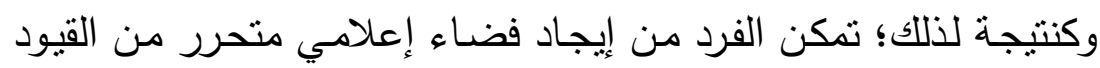

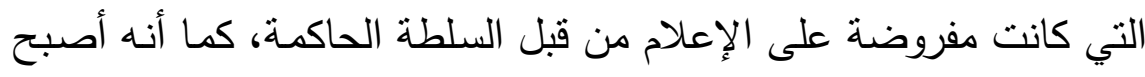

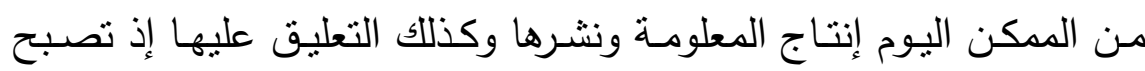
المعلومة المتوافرة في هذا الفضاء محل نقاش وتحليل من طرف مستخدمي 


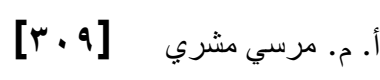

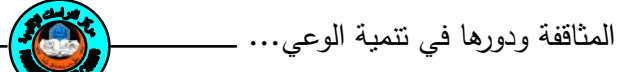

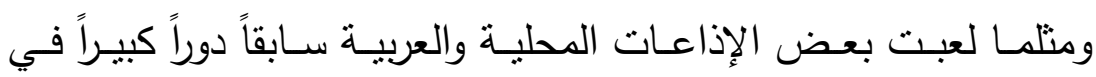

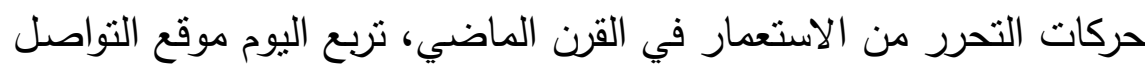
الاجتماعي facebook على عرش وسائل الإعلام.

\section{خلاصة}

إذن فالتثاقف هو العملية التي يكتسب الفرد أو الجماعـة عن طريقها

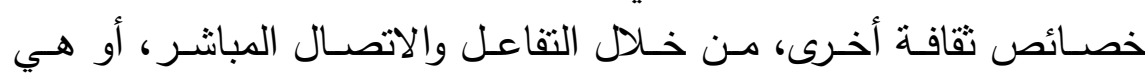

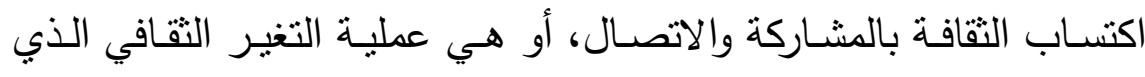

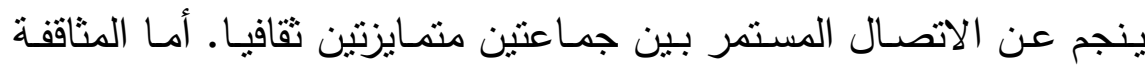
acculturation

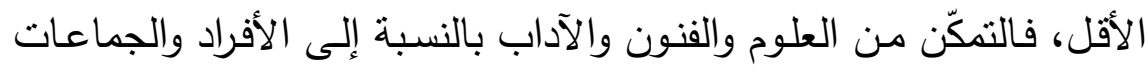

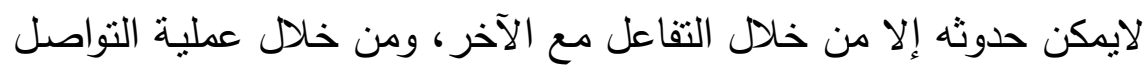

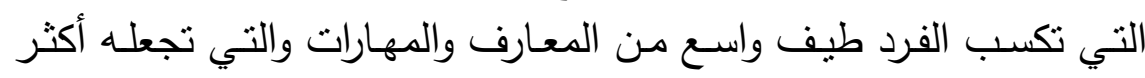

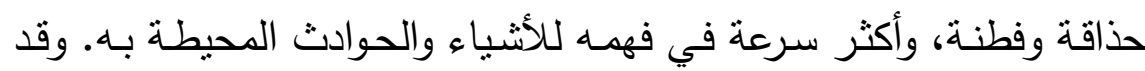

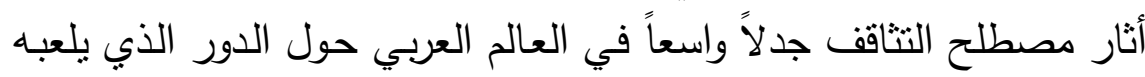

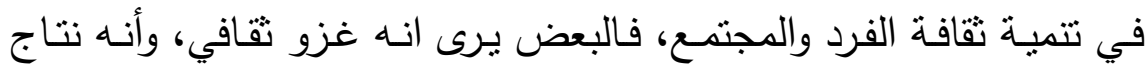

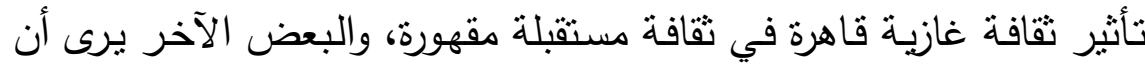

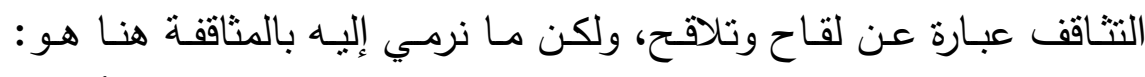

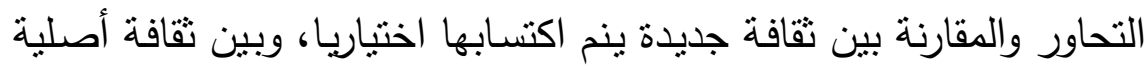

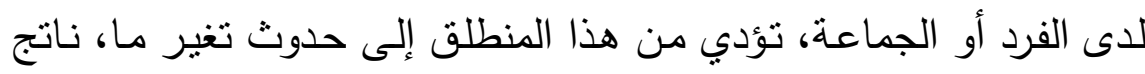

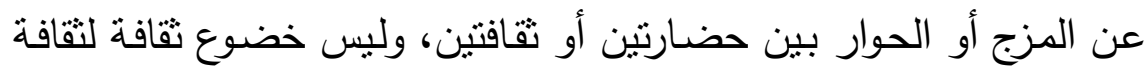
أخرى. 
وعلى الرغم من أن عملية التثاقف في الماضي كانت لا تتم إلا عندما ينتقل أفراد من مجتمعهم الأصلي للاستقرار في مجتمع أخر مختلف عنهم الخه

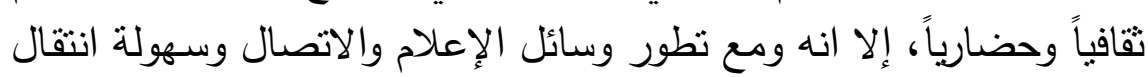

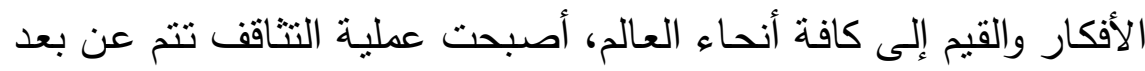

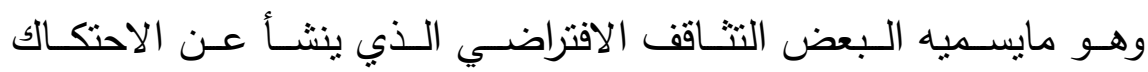
الافتراضي لا الفعلي بين الأفراد والجماعات من مختلف المشارب الحضارية لينموا نقافتهم وبثروا ثقافة أخرى على حد سواء، وتمثنل تقنية الاتصـال أهم

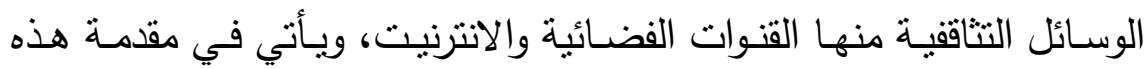

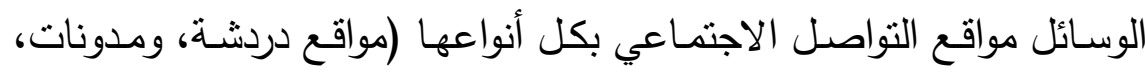

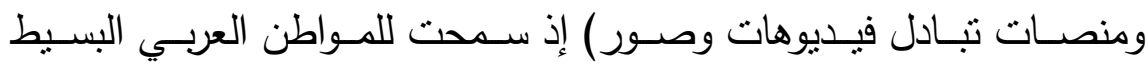
بالتواصل مـع أقرانه من الجنسيات الأخرى وتبـادل الخبرات الحياتيـة وتبـادل

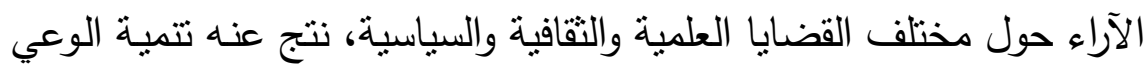
الذاتي للفرد العربـي بكل حقوقـه المهضـومة، وحرياتـه المصـادرة، وسـمح لـه

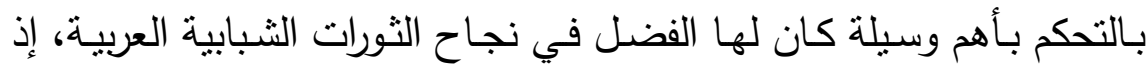
تمكن من خلال وسائل التواصل تعبئة الرأي العام المحلي والعربي، وتجنيده للقيام باحتجاجات ومظاهرات سلمية منظمة بطريقة غالطت الأنظمة الأمنية

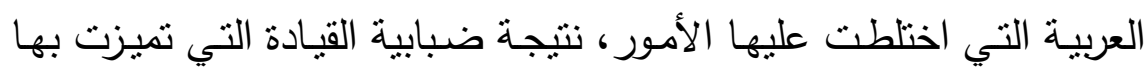
الثورة، والاعتقاد التقليدي السـائد لدى النخب العربيـة أن التحركات الثـعبية

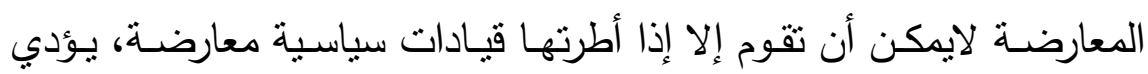
القضاء عليها إلى إخماد نيران الثورة، كما أسهمت وسائل الإعلام الاجتماعية إنهات في نقل أخبار الثورة ومختلف الممارسـات التعسفية والقمعيـة التي استعملها النظام، ومن ثم كسرت التعتيم الإعلامي الذي كانت تمارسه الأنظمة العربية، وكثف ممارساتها اللاإنسانية أمام الرأي العام العالمي، مما استوجي لإن تحركا

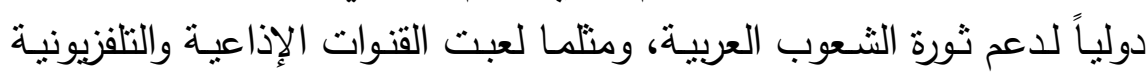
دورا مههـا في التروبج لقضـايا التحرر العربي كإذاعـة صـوت العـرب، كان 


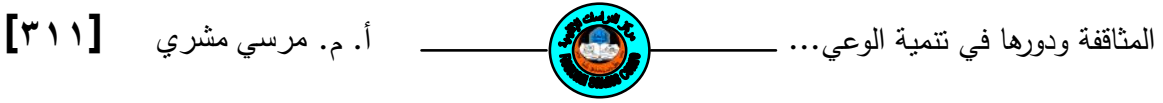

$$
\begin{aligned}
& \text { لوسـائل الإعـام المجتمعيـة دور في تتميـة الوعي السياسي للمواطن العربي، }
\end{aligned}
$$

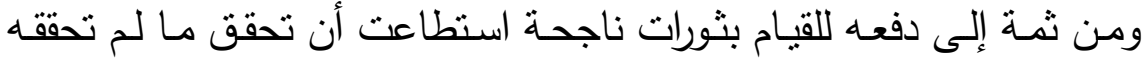

$$
\begin{aligned}
& \text { ثلاثث موجات ديمقراطية شهدها العالم. }
\end{aligned}
$$

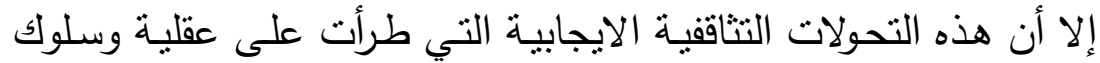

$$
\begin{aligned}
& \text { الفرد العربي كان لها نظيرها من التحولات السلبية، إذ تخلص الفرد التهابه العربي }
\end{aligned}
$$

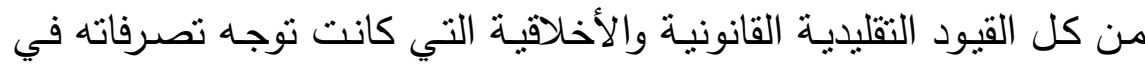

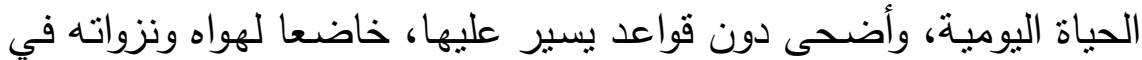

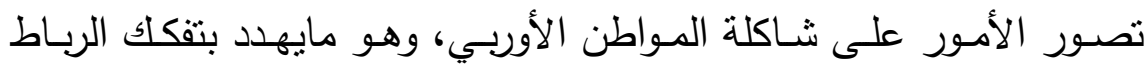

$$
\begin{aligned}
& \text { الاجتماعي للمجتمعات العربية، وتهديداً لهويته العربية الإسلامية. }
\end{aligned}
$$

\title{
Acculturation and its role in development of political awareness among Arab youth
}

\author{
Mussi Mashsi \\ Assistant Professor -Department of political science \\ University of chlef -Algeria
}

\begin{abstract}
The concept of acculturation (cultural adaptation) is considered from the modern social -cultural concepts in the interpretation of a dynamic people, and the various changes that have defined contemporary societies, the Arab nations led by their youth took part of the global acculturation campaign that globalization operates on a transfer to all parts of the world, carrying with it the values of democracy, freedom and justice, and cultural adaptation (acculturation) madein the Arabcommunities contributed in the success of the Arabic revolutions and the elimination of dictatorships and the peaceful transition to democracy in both Tunisia and Egypt, but it carries with it negative consequences primarily aims to change the Arab societies moral, intellectual and cultural system, and
\end{abstract}


eliminate the cultural objection of the Arab citizen and make him vulnerable to the cultural penetration and civilizational Entailment of Western civilization, according to the aims of globalization.

(1) ألهو امشدالله ابو هيف، المثاقفة والمثاقفة المعكوسة في الاستشراق تأثير الثقافة العربية الإسلامية http://science-islam.net/article.php3?id-article=620\&lang=ar

(2) Pascal Tisserant, anne-lorraine Wagner, et autre, Assimilation et discrimination : des attitudes convergentes,

www.prejuges-stereotypes.net/espaceDocumentaire/Tisserant.pdf, P2.

(T) محمد باسل سليمان، المثاقفة تفاعلات واستيعابات، مقالة منشورة بموقع http://www.ahewar.org/debat/show.art.asp?aid=132513

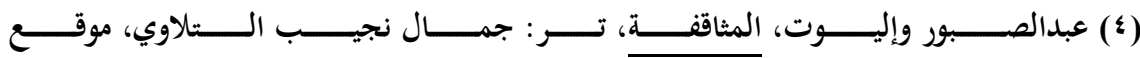

. $\wedge$ www.Kotobarabia.com

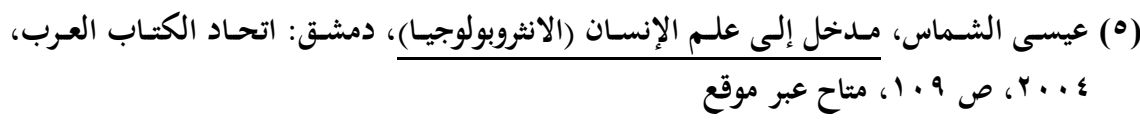

www.tourathtripoli.org/phocadownload/dirasset-fi-3ilm-alijtima3-al3am/ alinterpologia.pdf

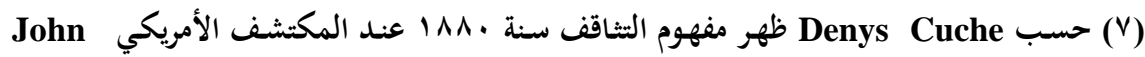

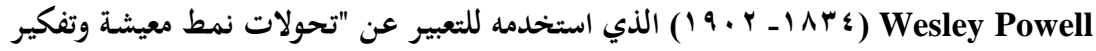

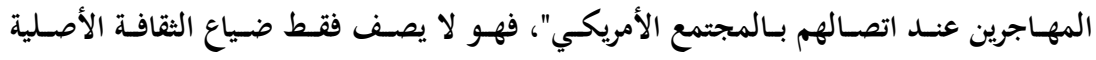

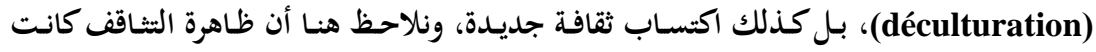

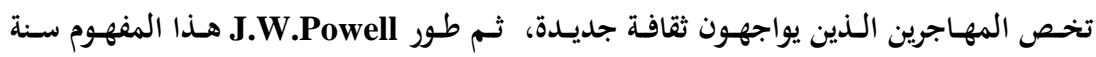

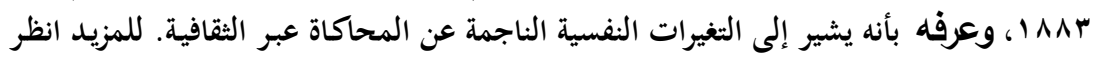

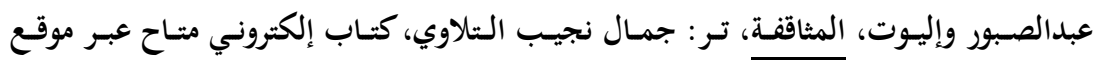




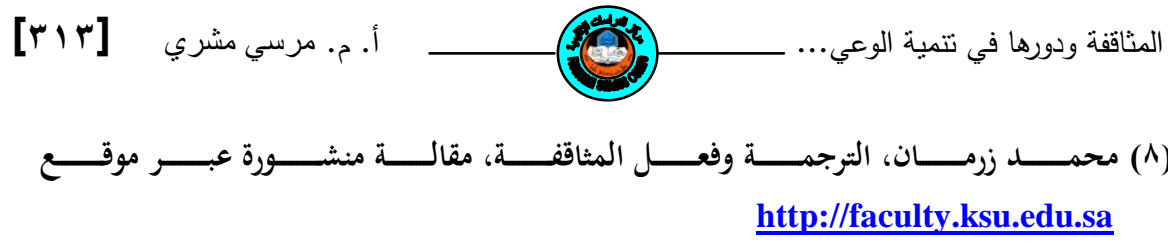

(9) Kevin.M.Chun, Pamela Balls Organista, Gerardo Marin, Acculturation, american psychological association, washington, 2000, P20.

$$
\begin{aligned}
& \text { Www.arab-ency.com ( • (1) الموسوعة العربية، المثاقفة، }
\end{aligned}
$$

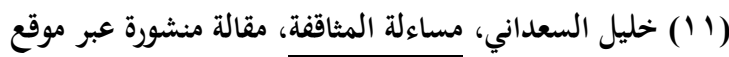

http://www.aljabriabed.net/n16_03saadani.htm

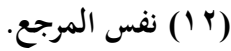

$$
\begin{aligned}
& \text { (T I I الطيب بوعزة، في دلالات مفهوم الاستلاب، }
\end{aligned}
$$

http://www.aljazeera.net/NR/exeres/05D73901-3069-40D3-B8CC-

C5F863E751B4.htm. $r \cdot v / \cdot v / r \diamond$ 。

( 1 \&) Groupe interdisciplinaire de recherché sur les Ameriques, Acculturation et hybridité culturelle, www.gira.info/fr/qui-sommes-nous/ problematique-etnotions-cles/transculturation-et-hybridite-culturelle.

$$
\begin{aligned}
& \text { (10 (1) عيسى الشماس، مرجع سابق الذكر. ص . 11. }
\end{aligned}
$$

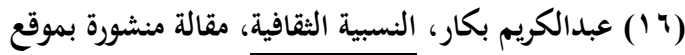

http://almoslim.net/node/112726

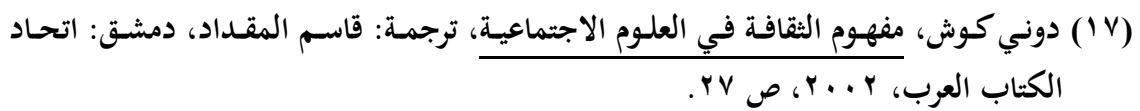

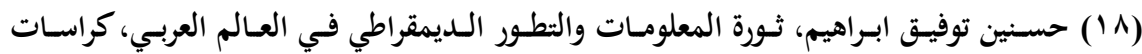

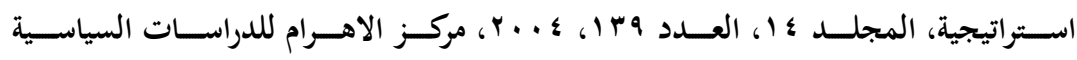

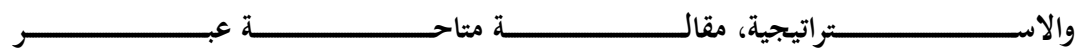

http://acpss.ahram.org.eg/ahram/2001/1/1/SB2K23.HTM

(9 1 (1) فاروق قهوجي دور المعلوماتية في تعزيز الهوية الوطنية والقومية للأطفال، ورقة مقدمة في إطار

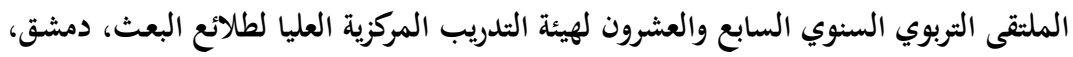

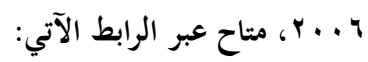

http://www.thenewalphabet.com/print_page140.html

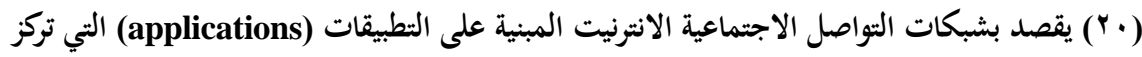

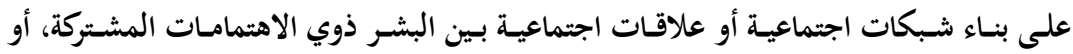


النشاطات المشتركة، وتعتمد مواقع الإعلام الاجتماعية أساسا على التمثيل لكل مستخدم (ملف

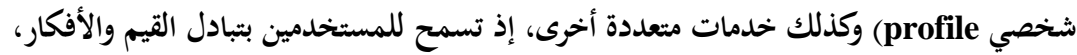
النشاطات، الأحداث، الاهتمامات في إطار شبكاتهم الشخصية، فضلا عن توسيع إطار تطبيقاتهم

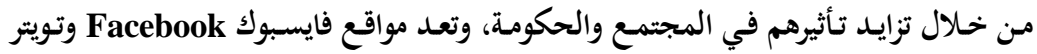
وماي سبايس My Space أهم مواقع الشبكات الاجتماعية رواجا في العالم.

( ${ }^{\prime}$ l) Philippe Torloting, Enjeux et perspectives des réseaux sociaux, mémoire de master en marketing, management et technologies de l'information, institut superieur du commerce de Paris, 2006, P2.

(YrY (Y) يوسف ورداني، ثقافة الشباب بين تحديات الانترنيت وعجز الدولة، معهد الوارف للدراسات الإنسانية،

http://www.alwaref.org/arabic/2009-02-26-01-56-19/76-2009-03-05-02-02-52

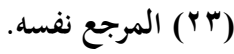

( ع r ) أشرف جلال حسن محمد، أثر التقنيات الاتصالية الحديثة (المواقع - المنتديات - المدونات) البديل، مقالة منشيل الرأي العام المجتمع العببي .. دراسة تشخيصية مقارنة في ضوء مدخل ملئل الإعلام

http://www.sudanja.net/articles.php?action=show\&id=87

(Y0) وتكمن النخبوية هنا في أنّ تعبئة الفلاحين وتنظيمهم للقيام بثورة مرتهن بوجود قيادة كارزمية أو

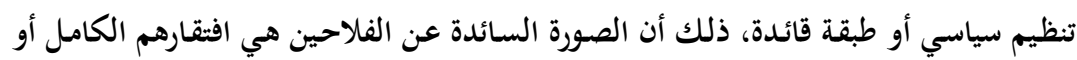

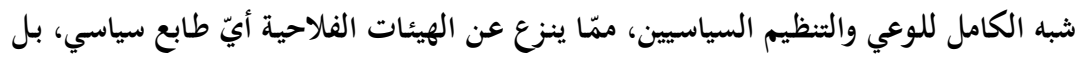
يجعلها تحركات عفوية أو تلقائية، وهو الاتجاه الذي سيطر على نظرة المؤرخين الهنود لثورات الفلاحين ضد الحكم الاستعماري البريطاني.

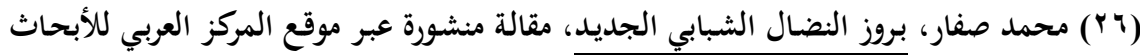
ودراسة السياسات،

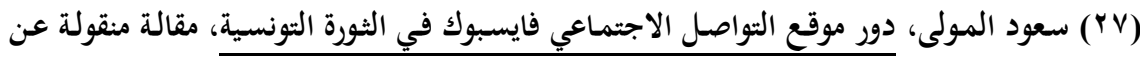
أسماء بن جبارة، متاحة عبر لون

http://saoudelmawla.blogspot.com/2011/07/blog-post_7842.html (Y^) (Yq) الممانعة هي امتناع عن مواجهة العدو، وعن التطوع لفعل ما يرغبه، وهي أيضا مرتبة وسطى بين مواجهة قد تنقلب إلى مجابهة مفتوحة؛ وبين "الاستسلام" للعدو. 
المثاقفة ودورها في تتمية الوعي...

( • (") عيسى الشماس، مرجع سابق، ص • 11. 